\title{
Triiodothyronine Regulates the Number and Morphological Development of Supporting Cells of organ of Corti During Critical Periods of Cochlear Development
}

\section{Xue Bai}

Huazhong University of Science and Technology

\section{Kai Xu}

Huazhong University of Science and Technology

\section{Sen Chen}

Huazhong University of Science and Technology

\section{Le Xie}

Huazhong University of Science and Technology

\section{Yue Qiu}

Huazhong University of Science and Technology

\section{Yu Sun ( $\nabla$ sunyu@hust.edu.cn )}

Tongji Medical College of Huazhong University of Science and Technology: Huazhong University of Science and Technology Tongji Medical College https://orcid.org/0000-0002-1771-3715

\section{Research Article}

Keywords: Triiodothyronine, Hearing loss, Cochlear remodeling, Organ of Corti

Posted Date: April 11th, 2022

DOI: https://doi.org/10.21203/rs.3.rs-1305245/v2

License: (c) (i) This work is licensed under a Creative Commons Attribution 4.0 International License. Read Full License 


\section{Abstract}

Thyroid hormones are essential for cochlear development and normal auditory function. Previous studies reported that excessive triiodothyronine (T3) accelerates the development of cochlear morphology and causes deafness in rodents. However, the pathophysiologic mechanism of T3-induced hearing loss and its effect on the remodeling of the organ of Corti (OC) remains unclear. In this study, neonatal wild-type (WT) mice were given T3 at different postnatal time points, and then auditory brainstem responses (ABR) and morphological changes of the $\mathrm{OC}$ were analyzed. Mice treated with $\mathrm{T} 3$ at postnatal day 0 (P0 group) or P1 (P1 group) showed severe deafness with disordered stereocilia of the outer hair cells (OHCs), and impaired mechanoelectrical transduction function of OHCs. In addition, administration of T3 at P0 or P1 resulted in the overproduction of Deiter-like cells (Deiter's cells, DCs, are supporting cells in the OC). These extra cells have phalangeal process structures similar to DCs, and are coupled with normal DCs by gap junctions. Furthermore, Sox2-haploinsufficient mice treated with T3 not only showed excess numbers of Deiter-like cells but also a large number of ectopic outer pillar cells (OPCs). In particular, these ectopic OPCs resulted in a great change in the morphology of the $\mathrm{OC}$, forming double tunnels of Corti structures. Together, our study provides new evidence for the dual roles of T3 in regulating both hair cell and supporting cell development, suggesting that it is possible to increase the reserve of supporting cells.

\section{Introduction}

The organ of Corti (OC), the auditory sensor by which sounds are converted into nerve impulses, is one of the most complex organ structures in mammals. The structure includes one row of inner hair cells (IHCs) and three rows of outer hair cells (OHCs) interdigitated among different types of supporting cells (SCs). The morphology of different SCs is distinct and few studies have focused on their biology and function[1]. Abnormal development of SCs induced by gene mutations, congenital cytomegalovirus infection, or thyroid disease can lead to severe hearing loss[2-4]. In addition, growing evidence suggests that well-formed SCs act as mediators of hair cell development, function and survival. Therefore, further research on the proliferation, maturation and development of SCs may increase our understanding of inner ear development and regeneration.

In rodents, the overall structure of the auditory epithelium is formed by the time of birth and continues to mature structurally until hearing begins at postnatal day $(P) 14$. During this period, HCs form V-shape stereocilia that accommodate the mechanoelectrical transduction (MET) channels. Deiters' cells (DCs), a type of SCs coupled with OHCs, extend phalangeal processes to provide structural support for OHCs. Inner and outer pillar cells (IPCs and OPCs) form triangular tunnels of Corti which support the whole OC. More different types of SCs, such as Hensen's cells, Claudius cells or inner sulcus cells, lie lateral to OHCs or IHCs. Many previous studies have focused on the molecules that regulate the proliferation and differentiation of $\mathrm{HCs}$ in order to achieve the purpose of restoring impaired hearing through $\mathrm{HC}$ regeneration strategies. Although ectopic HCs can be induced in the cochleae of newborn or adult mice, due to the lack of corresponding SCs and fine OC structure, these efforts still failed to restore hearing[57]. For the treatment of deafness, reconstruction of the entire $\mathrm{OC}$ may be a better but more difficult choice. 
It is particularly important to explore the development and regeneration of SCs. Interestingly, SC development is regulated by both local molecular pathways and systemic hormones.

Thyroid hormone regulates $\mathrm{OC}$ formation and the development of normal hearing $[8,9]$. Triiodothyronine (T3) is the main active form of thyroid hormone and acts on thyroid hormone receptors (TRs) to induce a series of physiological changes in target tissues $[10,11]$. In particular, animals with developmental hypothyroidism exhibit delayed opening of the TC[12,13]. Conversely, excess T3 can lead to death of SCs in the greater epithelial ridge (GER) and early opening of the tunnel of Corti with premature PCs[14, 15]. These findings suggest that T3 regulates the development of some types of SCs in the cochlea. In humans, thyroid related-diseases such as endemic iodine deficiency, congenital hypothyroidism, and resistance to T3 caused by mutations in TRs are associated with hearing loss[16-18]. In mice, secondary hypothyroidism caused by mutations in TRs results in permanent potassium channel dysfunction and impaired HC function[19-21]. Knockout of T3 transporters can lead to OHC death and developmental arrest of SCs in mice[22]. These findings suggest that T3 plays multiple roles in the function of HCs and development of SCs, especially in the fine structure formation of the OC.

To explore the effect of T3 on remodeling of the $\mathrm{OC}$ and development of SCs during early development, we administered T3 to neonatal mice at different time-points after birth. Our results show that excess T3 given at an early stage (P0 or P1) leads to severe hearing loss with abnormal stereocilia alignment and $\mathrm{HC}$ mechanosensory dysfunction. Moreover, mice in the P0 or P1 group showed an overproduction of Deiter-like cells. These extra cells expressed the functional marker acetylated a-tubulin, and are linked to adjacent DCs through gap junctions. A series of genes related to the development of cochlear sensory epithelium were significantly down-regulated in the T3 group. When Sox2 haploinsufficient mice were treated with T3 at P0, the number of DCs and OPCs increased significantly and cochlear epithelium was induced to form an OC with a double TC structure. Our finding suggests that excess T3 may lead to deafness by interfering with the normal stereocilia formation and amplification function of HCs. Excessive T3 or T3 combined with Sox2 downregulation can alter the fine structure of the $\mathrm{OC}$ by regulating development of SCs. Hormone action combined with key signaling pathways in the inner ear may be a potential research focus for regulating $\mathrm{OC}$ development and regeneration.

\section{Materials And Methods}

\section{Mouse models}

Neonatal mouse pups (C57BL6 mice) were subcutaneously injected with $2.0 \mu \mathrm{g}$ of T3 (T2877, Merck $\mathrm{KGaA}$, Darmstadt, Germany) in a volume of $10 \mu \mathrm{L}$, or the equivalent volume of saline, at P0 (the P0 group), P1 (the P1 group) or P3 (the P3 group). The concentration and total dose of T3 were based on previous studies and combined with data from our preliminary experiment; mice at this dose show an obvious audiological phenotype without causing gross developmental abnormalities[23]. To study the Notch signaling pathway, the Notch signaling inhibitor DAPT (HY-13027, MCE, Monmouth Junction, NJ, USA) was injected subcutaneously at PO $(250 \mathrm{nmol} / \mathrm{g})$, and then once per day for four consecutive 
days[24]. The preparation of T3 and DAPT was performed strictly in accordance with the instructions. Operators wore masks and gloves for self-protection, and waste disposal was standardized.

The Sox2 haploinsufficient mouse was a gift from Prof. Zhang at Southeast University in China. This line (Sox $2^{\mathrm{CreER} /+}$ ) was generated as an inserted targeted mutation in the single exon of the Sox 2 gene, resulting in Sox2 haploinsufficiency[25, 26]. Details of this line are given in the study by Zhang et al.[27]. Sox2 haploinsufficient mice treated with T3 at P0 (the Sox2 haplo + T3 group) were used to investigate their combined effects on cochlear development.

The genotyping primers for Sox $2^{\mathrm{CreER} /+}$ mice were as follows:

wild type (F) 5'-CTAGGCCACAGAATTGAAAGATCT-3';

wild type (R) 5'-GTAGGTGGAAATTCTAGCATCATCC-3';

mutant (F) 5'-GCG GTCTGGCAGTAAAAACTATC-3';

mutant (R) 5'-GTGAAACAGCAT TGCTGTCACTT-3'.

We performed all animal procedures according to protocols of the Committee on Animal Research of Tongji Medical College, Huazhong University of Science and Technology.

\section{Auditory brainstem response (ABR) and distortion product otoacoustic emission (DPOAE)}

The auditory thresholds of different groups were determined by ABR detection. The details of the ABR test were as described in our previous study[28]. Briefly, the mice were deeply anesthetized and three subcutaneous electrodes were placed at the vertex of the skull, the tested ear, and the contralateral ear. Click and tone burst stimuli at frequencies of $8,16,24,32$, and $40 \mathrm{kHz}$ were generated. The responses were recorded and determined by decreasing sound intensities from $90 \mathrm{~dB}$ in $10 \mathrm{~dB}$ steps, which narrowed to $5 \mathrm{~dB}$ steps near the threshold. The lowest sound intensity that could be recognized was determined to be the auditory threshold. DPOAE was measured at P20 ( $n=5$ mice in each group). The details of the DPOAE test were as described in our previous study[29].

\section{Immunofluorescence}

For activated caspase-3 immunostaining, mice were anesthetized and sacrificed at P6 or P11. For counting of cochlear HCs and DCs, mice ( $n=4$ in each group) were sacrificed at P18. The cochleae were carefully dissected in $0.01 \mathrm{M}$ PBS and then fixed in $4 \%$ paraformaldehyde. For flattened cochlear preparations, the samples were rinsed three times with PBS and decalcified with $10 \%$ disodium EDTA at $4^{\circ} \mathrm{C}$ for two days. Each stretched cochlear preparation was carefully dissected and incubated in blocking solution at room temperature for $1 \mathrm{~h}$, then incubated with polyclonal rabbit anti-myosin $7 \mathrm{a}$ antibody (1:500 dilution, 25-6790, Proteus Bio-Sciences, Ramona, CA, USA), polyclonal goat anti-Sox2 antibodies (1:100 dilution, sc-17320, Santa Cruz Biotechnology, Santa Cruz, CA, USA), monoclonal rabbit anti-a- 
tubulin antibody (1:200 dilution, ab179484, Abcam, Cambridge, UK), or polyclonal rabbit anti-Cx30 antibodies (1:200 dilution, 40-7400, Invitrogen, Carlsbad, CA, USA). After washing with PBST three times, the samples were incubated with fluorescent secondary antibodies (1:200 dilution, ANT032, Antgene, Wuhan, China) for $2 \mathrm{~h}$ in the dark. Phalloidin (P5282, Sigma, St Louis, MO, USA) was used for fluorescent visualization of HC F-actin, and nuclei were labeled with DAPI (C1005, Beyotime Biotechnology, Jiangsu, China). All images were scanned with a laser scanning confocal microscope (Nikon, Tokyo, Japan).

\section{Resin sections and transmission electron microscopy (TEM)}

The detailed methods for TEM have been described previously[29]. Briefly, mice were anesthetized and sacrificed at P18. After decalcification with $10 \%$ disodium EDTA for $48 \mathrm{~h}$, each sample was then immersed in $1 \%$ osmium tetroxide to post-fix for $1 \mathrm{~h}$. Samples were dehydrated through a graded ethanol series, before embedding in resin. Sections ( $1.5 \mu \mathrm{m}$ in thickness) were stained with toluidine blue (89640$5 \mathrm{G}$, Sigma-Aldrich) for observation, and ultrathin sections were stained with uranyl acetate and lead citrate and examined by TEM.

\section{Scanning electron microscopy (SEM)}

The morphology of $\mathrm{HC}$ stereocilia was observed by SEM at P18. As previously described[28], after fixation and decalcification, the cochleae were carefully dissected to expose the basilar membrane. Then the samples were dehydrated in increasing ethanol concentrations, dried (HCP-2, Critical Point Dryer, HITACHI, Tokyo, Japan), and sputter-coated with a layer of gold (Eiko Engineering, Tokyo, Japan). Stereocilia bundles were observed in the three turns of the cochlea. Images were captured using a scanning electron microscope (VEGA 3 LMU, Tescan, Brno, Czech Republic).

\section{FM1-43 Imaging}

FM1-43 loading of HCs was used to assess the function of mechano-transduction channels. Mice $(n=4$ in each group) were sacrificed at P18 and cochleae were quickly dissected from the temporal bones. The samples were incubated in a culture loaded with $4 \mu \mathrm{M}$ FM1-43 (T35356, Invitrogen) for $30 \mathrm{~s}$, and then fixed in $4 \%$ paraformaldehyde for $1 \mathrm{~h}$. Samples were washed with $0.01 \mathrm{M}$ PBS three times before imaging with a confocal microscope; all operations were performed at room temperature. DAPI was used for nuclear staining. Forty OHCs were selected from four mice in each group for fluorescence quantification. The intake of FM1-43 was determined by mean fluorescence intensity.

\section{Real-time quantitative polymerase chain reaction (RT-qPCR)}

Neonatal mice were injected with T3 at P0 for two consecutive days and then sacrificed at P4. The cochleae were removed and dissected in cold Hanks' balanced salt solution. The membranous cochlear duct sourced from one cochlea was used to generate one sample. The detailed methods for the RNA extraction and reverse transcription were as described previously[30]. RT-qPCR was performed in a Roche LightCycler 480 instrument (Roche Diagnostics Ltd, Basel, Switzerland). The transcriptional expression 
was normalized to the expression of GAPDH and the relative expression level between the control and T3 group was calculated using the $2^{-\Delta \Delta C T}$ method.

\section{Statistical analysis}

Data are presented as means \pm SEM and plotted using GraphPad Prism (Version 8.2.1, GraphPad Software Inc., La Jolla, CA, USA). Two-tailed, unpaired Student's t-tests and two-way ANOVA were performed using SPSS software (Version 19, IBM SPSS Statistics, IBM Corp., Armonk, NY, USA), a value of $P<0.05$ was considered to be statistically significant.

\section{Results}

\section{Excess T3 in the early postnatal days can induce hearing loss in mice}

To evaluate the effect of T3 treatments at different postnatal periods on auditory function in mice, ABR testing was performed at P18 ( $n=4$ mice in each group). Compared with the control group, the ABR-click thresholds increased significantly in the P0 or P1 group, while mice in the P3 group showed normal hearing (Fig. 1A). Mice in the P0 group showed severe deafness with mean thresholds above $80 \mathrm{~dB}$ SPL at $8-40 \mathrm{kHz}$, while mice in the $\mathrm{P} 1$ group displayed moderate to severe deafness with hearing thresholds at $8,16,24,32$, and $40 \mathrm{kHz}$ of $61.3 \pm 6.3,51.3 \pm 2.5,57.5 \pm 9.6,73.8 \pm 7.5$, and $90.0 \pm 0 \mathrm{~dB} \mathrm{SPL}$, respectively (Fig. 1B). Mice treated with T3 at P3 showed normal hearing at P18 (Fig. 1B).

\section{Excess T3 accelerates maturation of the GER and does not affect HC survival}

$\mathrm{HC}$ loss is a major cause of hearing loss. Thus, we analyzed the survival patterns of HCs in T3-treated mice. No substantial HC loss was observed in the different T3-treated groups at P18 (Fig. 2B-M). Although scattered losses of OHCs were occasionally observed in the basal turn of the PO group (white arrows, Fig. $2 \mathrm{G})$, statistical analysis showed that the number of OHCs was not significantly changed $(\mathrm{n}=$ $4, P>0.05$ ) (Fig. 2N).

In neonatal mice, the cochlea continues to develop structurally and functionally before hearing onset, and regression of the GER is a prominent event. During natural development, cells in the GER promote the development and maturation of sensory epithelium through programmed cell death. We performed activated casapase-3 staining to determine the apoptosis pattern of the GER in T3-treated mice. At P6, no activated caspase-3-positive (caspase-3+) cells were detected in the GER of control mice, while a large number of caspase-3 + cells were observed in the GER of the T3-treated group (Fig. 2P-S). In contrast, caspase-3 + cells were evident in the GER of control cochleae and were not detected in the T3-treated group at P11 (Fig. 2T-W). Statistical analysis showed that the number of caspase- $3+$ cells differed significantly between the two groups at P6 and P11 ( $n=4, P<0.01)$ (Fig. 20). 


\section{Excess T3 interferes with the morphology of HC stereocilia and the function of the MET channel}

In mammals, stereocilia are located in the cuticular plate of HCs and are responsible for converting mechanical vibrations generated by sound stimulation into electrical signals. Structural or functional defects of the stereocilia are one of the main causes of congenital or progressive deafness. We performed SEM to characterize the morphology of stereocilia in different T3-treated groups. In the control group, three rows of stereocilia formed V-shaped bundles in all turns (Fig. 3A-C, a-c). However, stereocilia bundles of $\mathrm{OHCs}$ in the apical and middle turns of the P0 or P1 group were disordered and lost their V-shaped structure. Interestingly, there were no obvious changes in the morphology of the stereocilia bundles in the basal turn of the P0 or P1 groups (Fig. 3D-I, d-i). In contrast, the morphology and arrangement of the $\mathrm{HC}$ stereocilia bundles were almost unaffected when T3 was given at P3 (Fig. 3J-L, $\mathrm{j}-\mathrm{I})$. These results suggest that the abnormal arrangement of the $\mathrm{HC}$ stereocilia bundle may be strongly associated with hearing loss caused by excess T3. In addition, FM1-43 loading of HCs was used to assess the function of the MET channel. Compared with the control group, the uptake of FM1-43 by OHCs in the T3 treatment group was reduced (Fig. 3M-P). Quantitative results showed that the relative fluorescence density of FM1-43 in OHCs of T3-treated mice decreased by $23.9 \pm 13.9 \%$ (Fig. 3Q). These results indicated that abnormalities of the $\mathrm{HC}$ stereocilia bundles and dysfunctions of the MET channel might be responsible for the hearing loss induced by excess T3. At both 10 and $16 \mathrm{kHz}$, the DPAOE input/output plots measured from the $\mathrm{PO}$ group decreased significantly compared with the control group (Fig. 3R, S). The level of DPAOE in the P0 group was significantly lower than that in the control group at all input levels $(P<0.001, \mathrm{n}=5$ in each group).

\section{Excess T3 induces overproduction of Deiter-like cells}

To investigate the effect of T3 on OC remodeling, mice were sacrificed at P18 and the SCs were labeled with Sox2 (white). Furthermore, phalloidin (red) was used to label the bases of the DCs and PCs. In the control group, the DCs were neatly arranged in three rows and the PCs were arranged in a single row in all turns (Fig. 4A-F). However, in the PO group, we observed four rows of DCs in the apical and middle turns, indicating the production of extra Deiter-like cells. In addition, the arrangement of Sox2-labeled SCs was disordered and the OPCs were jagged compared to the control group (Fig. 4G-J). The arrangement of DCs in the basal turn was almost unaffected in the P0 group (Fig. 4K, L). Statistical analysis showed that the number of DCs (including Deiter-like cells) was significantly increased in the apical and middle turns $(n=4, P<0.001)$ (Fig. 4M).

Next, we explored the effects of excess T3 administration at different time-points after birth on the development of the OC. We labeled DCs with Cx30, a protein subunit that constitutes gap junctions, which serves as a functional marker of DCs. In the control group, Cx30 signals (green) were evenly distributed along the boundaries of all DCs (including Deiter like cells) (Fig. 5A-C). In contrast in the P0 group, we observed that the Deiter-like cells also expressed $\mathrm{C} \times 30$, which suggested that these cells might have some of the functions of DCs (Fig. 5D, d, E, e). When T3 was given at P1, we also observed four rows of Cx30expressing DCs in the apical and middle turns (Fig. 5G, g, H, h). However, T3 given at P3 did not significantly affect the number of DCs (Fig. $5 J-L, j-I)$. Quantitative results showed that the number of 
DCs was significantly increased in apical and middle turns from the P0 and P1 groups $(n=4, P<0.01)$ (Fig. 5M). The distance between the feet of the IPCs and OPCs was also reduced in the apical and middle turns of the P0 and P1 groups (Fig. $5 \mathrm{~N}$ ). These parameters did not change significantly in the P3 group. Our results reveal that excess T3 regulates development of the OC, especially for DCs, in a narrow postnatal time window.

\section{Ultrastructural changes of SCs in T3-treated mice}

Radical sections of the cochlea revealed the nuclei of three rows of DCs in the control group (Fig. 6A, B). However, in the apical turn of the P0 group, we observed nuclei of four rows of DCs (Fig. 6C, D). In addition, ultrastructural examination showed the presence of three rows of DC cell bodies in the control group and bundles of microtubules and normal mitochondria in DCs (Fig. 6E-G). In the P0 group, we observed four rows of DC cell bodies (Fig. $6 \mathrm{~J}$ ). The phalangeal processes of extra DCs showed normal architecture of the bundles of microtubules and mitochondria (Fig. $6 \mathrm{I}, \mathrm{J}$ ), which indicated that the overproduced Deiter-like cell have a similar structure and function as normal DCs.

\section{Characterization of gene expression changes in the cochleae of T3-treated mice by realtime qPCR}

To investigate the mechanism involved in the T3-induced remodeling of the $\mathrm{OC}$, we performed qPCR to analyze the expression levels of a series of genes regulating development of the inner ear. The mRNA expression of Atoh1 and Sox2, two transcription factors that regulate development of HCs and SCs, was significantly down-regulated (Fig. 7A). However, the other important factors Pou4f3, Neurog1, and Gfi1 did not change significantly. In addition, we analyzed the Notch, Wnt, TGF $\beta$, and FGF signaling pathways as well as cell cycle signaling pathways and found that the transcription levels of Notch pathway-related genes, such as Notch1, Notch2, Notch2, Notch3, Jag1, Jag2, Hey1, Hey2, Hes1, Hes5, and DIl1 were significantly down-regulated (Fig. 7B). In contrast expression of FGF and most TGF $\beta$ signaling pathway genes did not change significantly, while only Smad4, Bmpr1b, and Ltbp1 were downregulated (Fig. 7C, D). In the Wnt pathway, the mRNA expression levels of Lgr5 and Wnt2b were significantly down-regulated and other related genes were not significantly changed (Fig. 7E). In addition, we found that the cell cycledependent kinases Cdk2 and Cdk4, and cell division cyclin Cdc25c, were down-regulated in cochleae of T3-treated mice (Fig. 7F). All these results suggest that T3 may lead to overproduction of DCs mainly through down-regulation of the Notch signaling pathway in early cochlear development.

\section{Effects of excess T3 combined with regulated Sox2 on the remodeling of $\mathrm{OC}$}

Recent studies have shown that Sox $2^{\mathrm{CreER} /+}$ mice exhibit Sox2 haploid insufficiency due to one of the alleles being replaced by CreER[26]. Using this characteristic, Sox $2^{\mathrm{CreER} /+}$ mice were injected with T3 to explore the effect of T3 combined with Sox2 downregulation on the development of SCs in the inner ear (Fig. 8A). In Sox2 haploinsufficient (Sox2 haplo) mice, three rows of DCs were neatly arranged, and Cx30 was observed at the edge of all DCs, almost as in the control group (Fig. 8B-G, b-g). In the T3 and the 
Sox2 haplo + T3 groups, four rows of DCs were observed in the apical and middle turns (Fig. 8H, I, K, L), and the quantified results showed no significant difference in the number of DCs between the T3 and the Sox2 haplo + T3 groups (Fig. 8N). However, two rows of OPCs were observed in the apical and middle turns of the Sox2 haplo + T3 group (Fig. 8K, K, L, I). Statistical analysis showed that the number of OPCs was significantly increased in the apical and middle turns of the Sox 2 haplo + T3 group $(n=4, P<0.01)$ (Fig. 80). These results suggest that T3 combined with Sox2 downregulation did not aggravate the overproduction of DCs induced by T3, but did induce overproduction of OPCs (white arrows, Fig. 9G). Moreover, extra OPCs in the Sox2 haplo + T3 group appeared to form new TCs (white arrowhead, Fig. 9G, $\mathrm{H}$ ), whereas in the T3 or Sox2 haplo group there was only a single TC (Fig. 9B, E). The yellow lines show the boundaries of the TC (Fig. 9B, E, and H). Additional OPCs were also observed in the radial sections of the cochlea, forming a new tunnel of Corti in the Sox2 haplo + T3 group (Fig. 9J). The magnified pictures show that bundles of microtubules were found in the areas with extra OPCs (white arrow, Fig. 9L), which were similar to normal IPCs or OPCs (white arrows, Fig. 9K and M). In addition, horizontal sections of the cochlea from the Sox2 haplo + T3 group also revealed additional OPCs (white arrows, Fig. 9N, 0). In magnified pictures, bundles of microtubules, which are a characteristic structure of mature PCs, were observed in the bodies of OPCs (white arrowheads, Fig. 9R) as well as extra OPCs (white arrowheads, Fig. 9P).

\section{Discussion}

\section{T3 is an exogenous factor involved in stereocilia formation by cochlear hair cells}

Over recent decades, a series of studies have focused on the role of thyroid hormones in fetal tissue differentiation and development[31]. Fetal nervous system development is highly sensitive to thyroid hormones, and maternal thyroid hormone disorder can cause fetal central nervous system symptoms including hearing, speech, and color vision impairments, and squint[32, 33]. A previous study showed that injections of T3 resulted in expected increases in serum T3 concentrations, with daily injections of 0.01 , 0.1 , and $2.0 \mu \mathrm{g}$ T3 up to P5 resulting in serum T3 levels that were increased approximately $12-, 80$-, and 280-fold, respectively[23]. T3-induced hearing loss in mice was concentration-dependent, with a dose of $0.1 \mu \mathrm{g} \mathrm{T3} / \mathrm{d}$ resulting in a threshold of approximately $70 \mathrm{~dB}$ SPL, whereas 1.5 or $2.0 \mu \mathrm{g} \mathrm{T3} / \mathrm{d}$ resulted in thresholds of more than or equal to $90 \mathrm{~dB}$ SPL[23]. A single injection of T3 at P0 resulted in significant hearing loss, whereas T3 given at P3 or later did not significantly change thresholds compared to salinetreated groups[15]. In this study, our results indicated that administration of excess T3 in the early postnatal period (P0 or P1) induced severe hearing loss in mice (Fig. 1). However, we did not observe significant degeneration of $\mathrm{HCs}$, suggesting that the cause of hearing loss is not simply $\mathrm{HC}$ death. When T3 was given at P3 (the P3 group), mice exhibited normal hearing at P18. Observations by ourselves and others have proven that P0-P2 is the critical period when deafness is caused by excess T3. In addition, caspase- 3 + cells were detected in the GER of the P0 group at P6, while apoptosis of the GER in the control group was not triggered at this time. However, a recent study by Borse et al. reported that 
macrophages were recruited into the GER region after initiation of GER regression during cochlear remodeling[14]. In this study, apoptotic signals in the GER region were detected at P5. This difference in timing may be due to differences in experimental technique and mouse strain used. Excess T3 advances the overall program of apoptosis, with regression of the GER initiated at P3 and creating a large cavity known as the inner spiral sulcus at P5 in the T3 treatment group. whereas in normal mice this process occurs at P7[15]. Premature degeneration of the GER triggered by T3 resulted in advanced opening of the tunnel of Corti. However, it remains unclear whether pre-maturation of the $\mathrm{OC}$ is directly related to hearing loss.

Stereocilia are mechanical sensors located in the cochlear sensory cells that convert sound stimuli into electrical signals, and normal auditory function depends on the organization and morphology of the stereocilia, thus they are thought to be critical for mammalian hearing and balance[34, 35]. Disorders of the stereocilia hair bundle structure are involved in various forms of congenital or progressive hearing loss[36-38]. We observed that administration of excess T3 in the early postnatal period (P0 or P1) caused a disturbance in the arrangement of the stereocilia of HCs, while the stereocilia showed normal structure in the P3 group. As shown in the picture (Fig. 3), the stereocilia hair bundles were disordered and varied in length in the T3-treated group. Similar to the effect on hearing, only P0-P2 administration of excess T3 resulted in abnormal stereocilia development. In addition, we observed reduced function of MET channels located at the apical junction of hair cell stereocilia in the P0 group (Fig. 3M-P).

Additionally, lower DPOAE levels were also found in the P0 group (Fig. 3R, S). This evidence indicated that the $\mathrm{OHC}$ abilities of mechanoelectrical transduction and amplification were both significantly impaired. Combined with analysis of the audiological phenotype and pathological phenotype, the results suggested that the disturbance of $\mathrm{HC}$ stereocilia and impaired function of $\mathrm{OHCs}$ were the main causes of hearing loss caused in the P0 and P1 groups. Based on the above results, excess T3 during the very early stage after birth does not affect $\mathrm{HC}$ survival but does cause dysfunction of HCs with abnormal development of stereocilia, which would be a novel mechanism of thyroid hormone-induced hearing loss.

\section{T3 regulates the production of SCs during critical periods of cochlear development}

Thyroid hormone receptors, deiodinase, and thyroid hormone transporter are widely expressed in the cochlea[23,39], which suggests that cochleae are the targets of thyroid hormone regulation of inner ear development. Forrest et al. reported that T3 regulates cochlear remodeling, which involves premature regression of the GER[15]. However, the effect of T3 on remodeling of the OC during early development has not been further explored. Here, we observed that treatment with T3 in the early development stage (P0 or P1) resulted in overproduction of DCs. Immunostaining results showed that these cells were connected with adjacent DCs by gap junctions. Microtubules, labeled by acetylated a-tubulin, were found in the body and phalangeal processes of the cells. This indicated that these Deiter-like cells may be functioning normally and can communicate intercellularly with adjacent SCs. We further speculate that they may be used as the preserve of DCs which can support new regenerated OHCs. Previous studies mainly focused on regulating SC proliferation by regulating proliferation-related genes. Our study showed 
that endocrine signals also contribute to the regulation of SC proliferation and development. In addition, T3 administration at P3 did not affect the number of DCs, suggesting that there was a narrow time window during which $\mathrm{T} 3$ regulated the proliferation of SCs.

In adult mammals, damage to sensory cells in the inner ear causes permanent hearing loss because degeneration of $\mathrm{HCs}$ is irreversible, whereas $\mathrm{HCs}$ can spontaneously regenerate from supporting cells (SCs) after injury in birds and fish[40]. Recent studies have shown that HCs can also be regenerated from SCs in newborn mice[41-43], however this spontaneous regenerative ability rapidly diminishes with age. Current research suggests that there are two mechanisms for $\mathrm{HC}$ regeneration in mammals, one of which is the direct trans-differentiation of SCs into new HCs[27]. In addition, the SCs or progenitor cells of the inner ear proliferate and then differentiate into new HCs[44-46]. The common feature of both pathways is that the new HCs are derived from SCs, which suggests that SCs in the inner ear are the key factor necessary for $\mathrm{HC}$ regeneration. Therefore, increasing the number of SCs is an important step in achieving $\mathrm{HC}$ regeneration. Multiple signaling pathways (Wnt, Notch, FGF, IGF, and Shh) are involved in the development and proliferation of SCs, and regulation of related genes leads to an increase in the number of SCs in the inner ear[47-49]. Our results reveal that endocrine signals regulate the proliferation of inner ear SCs during critical periods of cochlear development, providing a reference to coordinate the multifactor regulation of SC proliferation and $\mathrm{HC}$ regeneration.

Recent studies have shown that multiple signaling pathways are involved in regulating the development of HCs and SCs, among which the Notch signaling pathway plays an important role in this process[50]. In the sensory epithelium of the inner ear, HCs express the Notch ligands DII1, DII3, DII4, Jag1, and Jag2, while SCs express Notch downstream genes including Hes1, Hes5, Hey1, Hey2, and HeyL. Notchmediated lateral inhibition maintains SCs in a quiescent state, and suppression of Notch signaling by drugs or genetic ablation of Notch effector genes leads to excessive formation of HCs or overproduction of SCs[51, 52]. In our study, real-time quantitative PCR results showed that the expression of genes related to the Notch signaling pathway was significantly down-regulated. However, a combination of Notch inhibitors did not promote T3-induced overproduction of DCs, suggesting that the role of Notch signaling in T3-induced DC overproduction is ambiguous (Fig. S1). In the future, the effect of excess T3 on more Notch-related pathways should be explored. In addition, the expression of individual genes in some classical pathways that regulate DC proliferation was significantly altered, such as Smad4, Bmpr1b, Ltbp1 Lgr5, and Wnt2b which were significantly down-regulated, but the significance of these gene changes remains unclear.

\section{The combination of T3 and Sox2 haploinsufficiency regulates not only the number of SCs but also the fine structure of the $\mathrm{OC}$}

Expression of the transcription factor Sox2 was significantly down-regulated in the T3 group. Based on the characteristics of Sox $2^{\mathrm{CreER} /+}$ mice with Sox2 haploinsufficiency[26], we constructed a mouse model of T3 combined with down-regulation of Sox 2 by giving $T 3$ to Sox $2^{\mathrm{CreER} /+}$ mice. The results showed that excess T3 treatment combined with downregulation of Sox2 not only resulted in overproduction of DCs, 
but also led a to a large number of OPCs. The most exciting find was that these extra OPCs were obviously in a relatively mature state with plenty of microtubules. These extra OPCs combined with the original IPCs and OPCs to form double tunnel of Corti structures. In cochlear development, the formation of the tunnel of Corti is a milestone in $\mathrm{OC}$ maturation. These extra tunnels of Corti can provide structural support for the whole OC in the Sox2 haplo + T3 group. This phenomenon indicates that T3 combined with local transcription factors (such as Sox2) may regulate and even induce formation of the complex spatial structure of the OC. Our findings may provide a theoretical basis for global OC regeneration. The key signaling pathway mediating SC proliferation and remodeling of the fine structure of the $\mathrm{OC}$ induced by T3 still needs further study. The idea that endocrine signaling may combine with gene programming to regulate cochlear development and SC proliferation is a novel proposal that will open up new aspects of the field of study and potentially lead to the development of new therapies.

\section{Conclusion}

Our results suggest that (I) T3 is an exogenous factor involved in stereocilia formation and $\mathrm{HC}$ functions; (II) T3 regulates the production of SCs during critical periods of cochlear development; and (III) the combination of T3 and Sox2 haploinsufficiency regulates not only the number of SCs but also the structure of the $\mathrm{OC}$. Our findings provide new evidence for the role of endocrine signaling in regulating the development of cochlear sensory epithelium.

\section{Declarations}

\section{Acknowledgments}

This work was supported by grants from The National Nature Science Foundation of China (Nos: 81771003 and 82071508).

\section{Conflict of interest}

The authors declare that they have no conflict of interest.

\section{Author Contributions}

All authors contributed to the study's conception and design. YS and SC conceived and designed the experiments; $X B, K X$ and $S C$ performed the experiments; $K X$ and $X B$ analyzed the data; $K X, L X$ and $Y Q$ contributed to the mouse breeding; $X B$ and $S C$ wrote the paper. $Y S$ reviewed and edited the manuscript. All authors read and approved the final manuscript.

\section{Data Availability}

The datasets generated are available from the corresponding author on reasonable request.

\section{Ethics approval}


All animal experiments were reviewed and approved by the Union Hospital of Tongji Medical College, Huazhong University of Science and Technology.

\section{Consent to publish}

All authors consent to the publication of the manuscript in CMLS.

\section{References}

1. Wu DK, Kelley MW (2012) Molecular mechanisms of inner ear development. Cold Spring Harb Perspect Biol 4(8):a008409. doi:10.1101/cshperspect.a008409

2. Melnick M, Jaskoll T (2015) CMV-induced embryonic mouse organ of corti dysplasia: Network architecture of dysfunctional lateral inhibition. Birth defects research Part A, Clinical and molecular teratology. 103:573-582. 10.1002/bdra.23386. 7

3. Chen S, Xie L, Xu K, Cao HY, Wu X, Xu XX, Sun Y, Kong WJ (2018) Developmental abnormalities in supporting cell phalangeal processes and cytoskeleton in the Gjb2 knockdown mouse model. Dis Model Mech 11(2). doi:10.1242/dmm.033019

4. Uziel A, Marot M, Rabie A (1985) Corrective effects of thyroxine on cochlear abnormalities induced by congenital hypothyroidism in the rat. II. Electrophysiological study. Brain Res 351(1):123-127. doi:10.1016/0165-3806(85)90237-8

5. Walters BJ, Coak E, Dearman J, Bailey G, Yamashita T, Kuo B, Zuo J (2017) In Vivo Interplay between p27(Kip1), GATA3, ATOH1, and POU4F3 Converts Non-sensory Cells to Hair Cells in Adult Mice. Cell Rep 19(2):307-320. doi:10.1016/j.celrep.2017.03.044

6. Mizutari K, Fujioka M, Hosoya M, Bramhall N, Okano HJ, Okano H, Edge AS (2013) Notch inhibition induces cochlear hair cell regeneration and recovery of hearing after acoustic trauma. Neuron 77(1):58-69. doi:10.1016/j.neuron.2012.10.032

7. Shu Y, Li W, Huang M, Quan YZ, Scheffer D, Tian C, Tao Y, Liu X, Hochedlinger K, Indzhykulian AA, Wang Z, Li H, Chen ZY (2019) Renewed proliferation in adult mouse cochlea and regeneration of hair cells. Nat Commun 10(1):5530. doi:10.1038/s41467-019-13157-7

8. Uziel A, Gabrion J, Ohresser M, Legrand C (1981) Effects of hypothyroidism on the structural development of the organ of Corti in the rat. Acta Otolaryngol 92(5-6):469-480. doi:10.3109/00016488109133286

9. Knipper M, Zinn C, Maier H, Praetorius M, Rohbock K, Köpschall I, Zimmermann U (2000) Thyroid hormone deficiency before the onset of hearing causes irreversible damage to peripheral and central auditory systems. J Neurophysiol 83(5):3101-3112. doi:10.1152/jn.2000.83.5.3101

10. Bianco AC, Salvatore D, Gereben B, Berry MJ, Larsen PR (2002) Biochemistry, cellular and molecular biology, and physiological roles of the iodothyronine selenodeiodinases. Endocr Rev 23(1):38-89. doi:10.1210/edrv.23.1.0455 
11. St Germain DL, Galton VA, Hernandez A (2009) Minireview: Defining the roles of the iodothyronine deiodinases: current concepts and challenges. Endocrinology 150(3):1097-1107. doi:10.1210/en.2008-1588

12. Griffith AJ, Szymko YM, Kaneshige M, Quiñónez RE, Kaneshige K, Heintz KA, Mastroianni MA, Kelley MW, Cheng SY (2002) Knock-in mouse model for resistance to thyroid hormone (RTH): an RTH mutation in the thyroid hormone receptor beta gene disrupts cochlear morphogenesis. J Association Res Otolaryngology: JARO 3(3):279-288. doi:10.1007/s101620010092

13. Ng L, Goodyear RJ, Woods CA, Schneider MJ, Diamond E, Richardson GP, Kelley MW, Germain DL, Galton VA, Forrest D (2004) Hearing loss and retarded cochlear development in mice lacking type 2 iodothyronine deiodinase. Proc Natl Acad Sci U S A 101(10):3474-3479. doi:10.1073/pnas.0307402101

14. Borse V, Kaur T, Hinton A, Ohlemiller K, Warchol ME (2021) Programmed Cell Death Recruits Macrophages Into the Developing Mouse Cochlea. Front cell Dev biology 9:777836. doi:10.3389/fcell.2021.777836

15. Peeters RP, Ng L, Ma M, Forrest $D$ (2015) The timecourse of apoptotic cell death during postnatal remodeling of the mouse cochlea and its premature onset by triiodothyronine (T3). Mol Cell Endocrinol 407:1-8. doi:10.1016/j.mce.2015.02.025

16. DeLong GR, Stanbury JB, Fierro-Benitez R (1985) Neurological signs in congenital iodine-deficiency disorder (endemic cretinism). Dev Med Child Neurol 27(3):317-324. doi:10.1111/j.14698749.1985.tb04542.x

17. Lichtenberger-Geslin L, Dos Santos S, Hassani Y, Ecosse E, Van Den Abbeele T, Léger J (2013) Factors associated with hearing impairment in patients with congenital hypothyroidism treated since the neonatal period: a national population-based study. J Clin Endocrinol Metab 98(9):3644-3652. doi:10.1210/jc.2013-1645

18. Ferrara AM, Onigata K, Ercan O, Woodhead H, Weiss RE, Refetoff S (2012) Homozygous thyroid hormone receptor $\beta$-gene mutations in resistance to thyroid hormone: three new cases and review of the literature. J Clin Endocrinol Metab 97(4):1328-1336. doi:10.1210/jc.2011-2642

19. Rusch A, Ng L, Goodyear R, Oliver D, Lisoukov I, Vennstrom B, Richardson G, Kelley MW, Forrest D (2001) Retardation of cochlear maturation and impaired hair cell function caused by deletion of all known thyroid hormone receptors. J neuroscience: official J Soc Neurosci 21(24):9792-9800. doi:10.1523/jneurosci.21-24-09792.2001

20. Mustapha M, Fang Q, Gong TW, Dolan DF, Raphael Y, Camper SA, Duncan RK (2009) Deafness and permanently reduced potassium channel gene expression and function in hypothyroid Pit1 dw mutants. J neuroscience: official J Soc Neurosci 29(4):1212-1223. doi:10.1523/jneurosci.495708.2009

21. Richter CP, Münscher A, Machado DS, Wondisford FE, Ortiga-Carvalho TM (2011) Complete activation of thyroid hormone receptor $\beta$ by T3 is essential for normal cochlear function and 
morphology in mice. Cell Physiol biochemistry: Int J experimental Cell Physiol Biochem Pharmacol 28(5):997-1008. doi:10.1159/000335812

22. Sharlin DS, Ng L, Verrey F, Visser TJ, Liu Y, Olszewski RT, Hoa M, Heuer H, Forrest D (2018) Deafness and loss of cochlear hair cells in the absence of thyroid hormone transporters Slc16a2 (Mct8) and Slc16a10 (Mct10). Sci Rep 8(1):4403. doi:10.1038/s41598-018-22553-w

23. Ng L, Hernandez A, He W, Ren T, Srinivas M, Ma M, Galton VA, St Germain DL, Forrest D (2009) A protective role for type 3 deiodinase, a thyroid hormone-inactivating enzyme, in cochlear development and auditory function. Endocrinology 150(4):1952-1960. doi:10.1210/en.2008-1419

24. Tanimizu N, Kaneko K, Itoh T, Ichinohe N, Ishii M, Mizuguchi T, Hirata K, Miyajima A, Mitaka T (2016) Intrahepatic bile ducts are developed through formation of homogeneous continuous luminal network and its dynamic rearrangement in mice. Hepatology (Baltimore MD) 64(1):175-188. doi:10.1002/hep.28521

25. Arnold K, Sarkar A, Yram MA, Polo JM, Bronson R, Sengupta S, Seandel M, Geijsen N, Hochedlinger K (2011) Sox2(+) adult stem and progenitor cells are important for tissue regeneration and survival of mice. Cell Stem Cell 9(4):317-329. doi:10.1016/j.stem.2011.09.001

26. Atkinson PJ, Dong Y, Gu S, Liu W, Najarro EH, Udagawa T, Cheng AG (2018) Sox2 haploinsufficiency primes regeneration and Wnt responsiveness in the mouse cochlea. J Clin Invest 128(4):1641-1656. doi:10.1172/JCI97248

27. Zhang S, Zhang Y, Dong Y, Guo L, Zhang Z, Shao B, Qi J, Zhou H, Zhu W, Yan X, Hong G, Zhang L, Zhang X, Tang M, Zhao C, Gao X, Chai R (2020) Knockdown of Foxg1 in supporting cells increases the trans-differentiation of supporting cells into hair cells in the neonatal mouse cochlea. Cell Mol Life Sci 77(7):1401-1419. doi:10.1007/s00018-019-03291-2

28. Chen S, Xu K, Xie L, Cao HY, Wu X, Du AN, He ZH, Lin X, Sun Y, Kong WJ (2018) The spatial distribution pattern of Connexin26 expression in supporting cells and its role in outer hair cell survival. Cell Death Dis 9(12):1180. doi:10.1038/s41419-018-1238-x

29. Xie L, Chen S, Xu K, Cao HY, Du AN, Bai X, Sun Y, Kong WJ (2019) Reduced postnatal expression of cochlear Connexin26 induces hearing loss and affects the developmental status of pillar cells in a dose-dependent manner. Neurochem Int 128:196-205. doi:10.1016/j.neuint.2019.04.012

30. Xu K, Chen S, Xie L, Qiu Y, Bai X, Liu XZ, Zhang HM, Wang XH, Jin Y, Sun Y, Kong WJ (2020) Local Macrophage-Related Immune Response Is Involved in Cochlear Epithelial Damage in Distinct Gjb2Related Hereditary Deafness Models. Front cell Dev biology 8:597769. doi:10.3389/fcell.2020.597769

31. Prezioso G, Giannini C, Chiarelli F (2018) Effect of Thyroid Hormones on Neurons and Neurodevelopment. Hormone Res paediatrics 90(2):73-81. doi:10.1159/000492129

32. Moog NK, Entringer S, Heim C, Wadhwa PD, Kathmann N, Buss C (2017) Influence of maternal thyroid hormones during gestation on fetal brain development. Neuroscience 342:68-100. doi:10.1016/j.neuroscience.2015.09.070 
33. Ng L, Lyubarsky A, Nikonov SS, Ma M, Srinivas M, Kefas B, St Germain DL, Hernandez A, Pugh EN Jr, Forrest D (2010) Type 3 deiodinase, a thyroid-hormone-inactivating enzyme, controls survival and maturation of cone photoreceptors. J neuroscience: official J Soc Neurosci 30(9):3347-3357. doi:10.1523/jneurosci.5267-09.2010

34. Gillespie PG, Müller U (2009) Mechanotransduction by hair cells: models, molecules, and mechanisms. Cell 139(1):33-44. doi:10.1016/j.cell.2009.09.010

35. Hudspeth AJ (2008) Making an effort to listen: mechanical amplification in the ear. Neuron 59(4):530-545. doi:10.1016/j.neuron.2008.07.012

36. Liu Y, Qi J, Chen X, Tang M, Chu C, Zhu W, Li H, Tian C, Yang G, Zhong C, Zhang Y, Ni G, He S, Chai R, Zhong G (2019) Critical role of spectrin in hearing development and deafness. Sci Adv 5(4):eaav7803. doi:10.1126/sciadv.aav7803

37. Katsuno T, Belyantseva IA, Cartagena-Rivera AX, Ohta K, Crump SM, Petralia RS, Ono K, Tona R, Imtiaz A, Rehman A, Kiyonari H, Kaneko M, Wang YX, Abe T, Ikeya M, Fenollar-Ferrer C, Riordan GP, Wilson EA, Fitzgerald TS, Segawa K, Omori K, Ito J, Frolenkov GI, Friedman TB, Kitajiri SI (2019) TRIOBP-5 sculpts stereocilia rootlets and stiffens supporting cells enabling hearing. JCl insight 4(12). doi:10.1172/jci.insight.128561

38. Liu C, Luo N, Tung CY, Perrin BJ, Zhao B (2018) GRXCR2 Regulates Taperin Localization Critical for Stereocilia Morphology and Hearing. Cell Rep 25(5):1268-1280e1264. doi:10.1016/j.celrep.2018.09.063

39. Sharlin DS, Visser TJ, Forrest D (2011) Developmental and cell-specific expression of thyroid hormone transporters in the mouse cochlea. Endocrinology 152(12):5053-5064. doi:10.1210/en.2011-1372

40. Rubel EW, Furrer SA, Stone JS (2013) A brief history of hair cell regeneration research and speculations on the future. Hear Res 297:42-51. doi:10.1016/j.heares.2012.12.014

41. Bramhall NF, Shi F, Arnold K, Hochedlinger K, Edge AS (2014) Lgr5-positive supporting cells generate new hair cells in the postnatal cochlea. Stem cell reports 2(3):311-322. doi:10.1016/j.stemcr.2014.01.008

42. Chai R, Kuo B, Wang T, Liaw EJ, Xia A, Jan TA, Liu Z, Taketo MM, Oghalai JS, Nusse R, Zuo J, Cheng AG (2012) Wnt signaling induces proliferation of sensory precursors in the postnatal mouse cochlea. Proc Natl Acad Sci U S A 109(21):8167-8172. doi:10.1073/pnas.1202774109

43. Zhang Y, Guo L, Lu X, Cheng C, Sun S, Li W, Zhao L, Lai C, Zhang S, Yu C, Tang M, Chen Y, Chai R, Li H (2018) Characterization of Lgr6 + Cells as an Enriched Population of Hair Cell Progenitors Compared to Lgr5 + Cells for Hair Cell Generation in the Neonatal Mouse Cochlea. Front Mol Neurosci 11:147. doi:10.3389/fnmol.2018.00147

44. Shi F, Kempfle JS, Edge AS (2012) Wnt-responsive Lgr5-expressing stem cells are hair cell progenitors in the cochlea. J neuroscience: official J Soc Neurosci 32(28):9639-9648. doi:10.1523/jneurosci.1064-12.2012 
45. Lush ME, Diaz DC, Koenecke N, Baek S, Boldt H, St Peter MK, Gaitan-Escudero T, Romero-Carvajal A, Busch-Nentwich EM, Perera AG, Hall KE, Peak A, Haug JS, Piotrowski T (2019) scRNA-Seq reveals distinct stem cell populations that drive hair cell regeneration after loss of Fgf and Notch signaling. elife 8. doi:10.7554/elife.44431

46. Cox BC, Chai R, Lenoir A, Liu Z, Zhang L, Nguyen DH, Chalasani K, Steigelman KA, Fang J, Rubel EW, Cheng AG, Zuo J (2014) Spontaneous hair cell regeneration in the neonatal mouse cochlea in vivo. Development 141(4):816-829. doi:10.1242/dev.103036

47. Rocha-Sanchez SM, Scheetz LR, Contreras M, Weston MD, Korte M, McGee J, Walsh EJ (2011) Mature mice lacking Rbl2/p130 gene have supernumerary inner ear hair cells and supporting cells. J neuroscience: official J Soc Neurosci 31(24):8883-8893. doi:10.1523/jneurosci.5821-10.2011

48. Tateya T, Imayoshi I, Tateya I, Ito J, Kageyama R (2011) Cooperative functions of Hes/Hey genes in auditory hair cell and supporting cell development. Dev Biol 352(2):329-340.

doi:10.1016/j.ydbio.2011.01.038

49. Maass JC, Berndt FA, Cánovas J, Kukuljan M (2013) p27Kip1 knockdown induces proliferation in the organ of Corti in culture after efficient shRNA lentiviral transduction. J Association Res Otolaryngology: JARO 14(4):495-508. doi:10.1007/s10162-013-0383-2

50. Kelley MW (2006) Regulation of cell fate in the sensory epithelia of the inner ear. Nat Rev Neurosci 7(11):837-849. doi:10.1038/nrn1987

51. Kiernan AE, Cordes R, Kopan R, Gossler A, Gridley T (2005) The Notch ligands DLL1 and JAG2 act synergistically to regulate hair cell development in the mammalian inner ear. Development 132(19):4353-4362. doi:10.1242/dev.02002

52. Li S, Mark S, Radde-Gallwitz K, Schlisner R, Chin MT, Chen P (2008) Hey2 functions in parallel with Hes1 and Hes5 for mammalian auditory sensory organ development. BMC Dev Biol 8:20. doi:10.1186/1471-213x-8-20

\section{Figures}

A

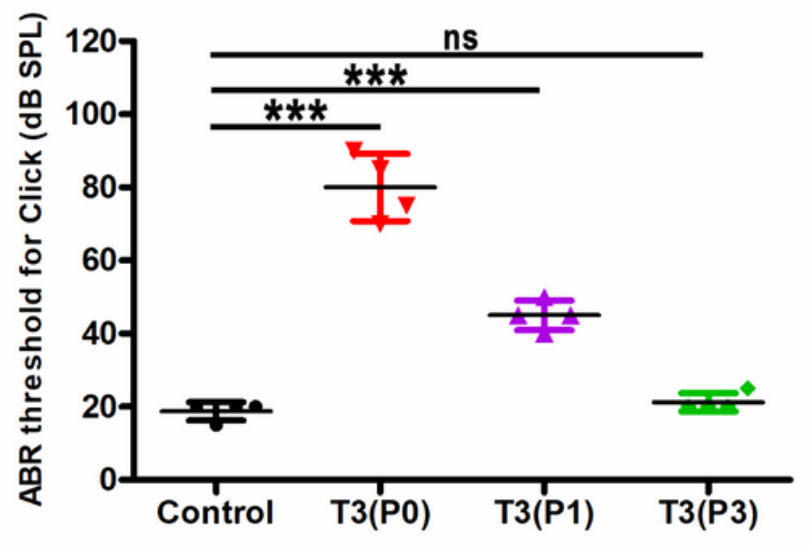

B

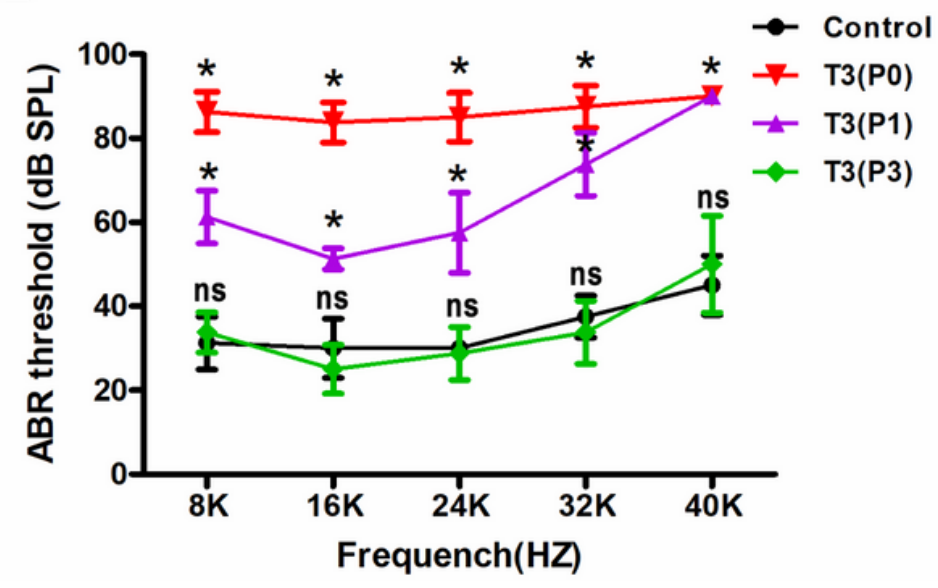


Figure 1

Excessive T3 in the early postnatal days can induce hearing loss in mice. (A) ABR-click thresholds in control and different T3-treated groups. (B) Comparison of tone-burst thresholds in different groups. ns: not significant, ${ }^{\star} \mathrm{P}<0.05$, *** $\mathrm{P}<0.001$.

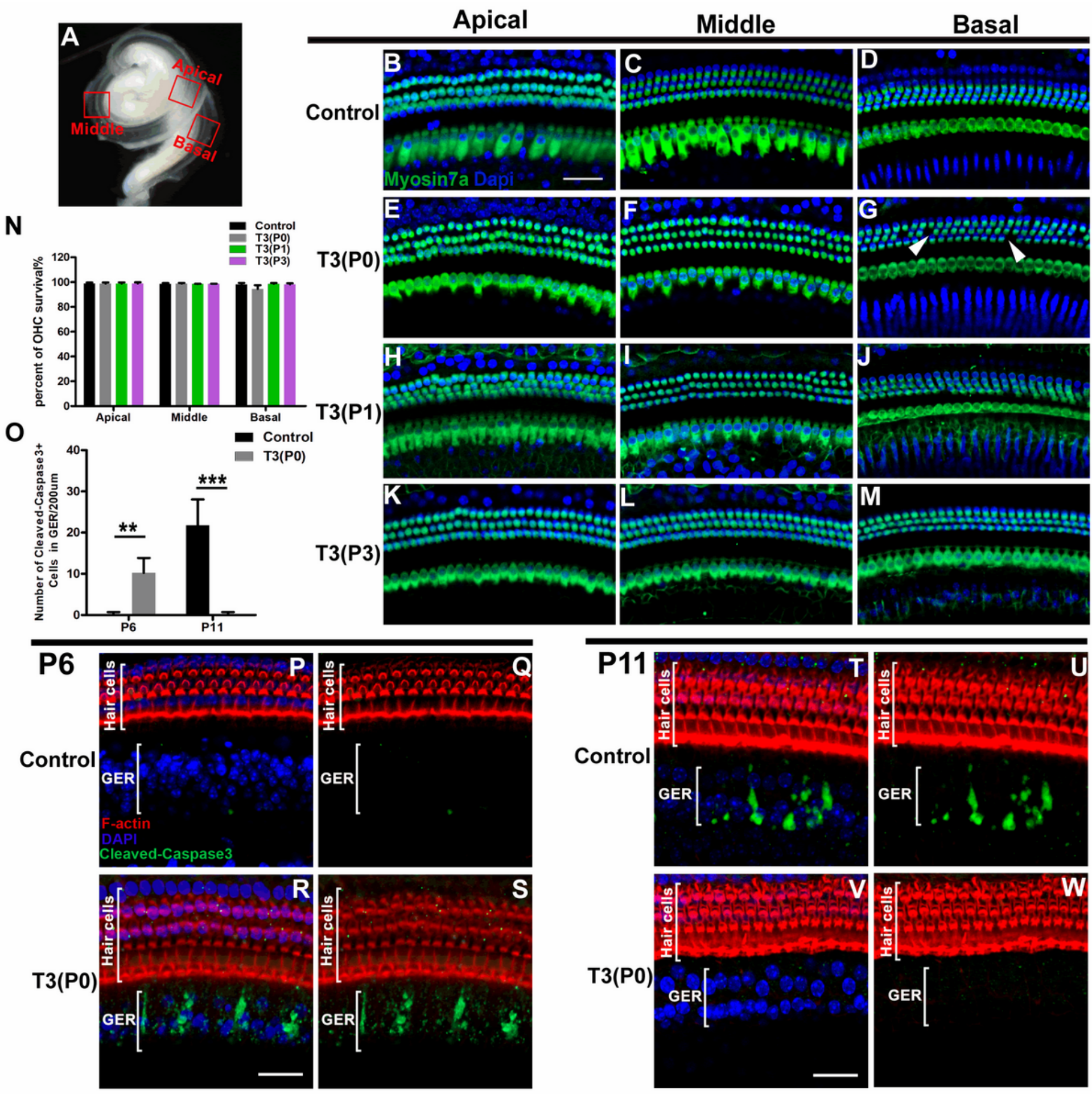

Figure 2 
Excessive T3 accelerates the maturation of GER. (A) An overall image of the cochlea to show the different turns of the basilar membrane. (B-M) Representative confocal images of HCs (Myosin7a, green) of apical, middle, and basal turns in different groups at $\mathrm{P} 18$. White arrowheads indicate sporadic missing $\mathrm{OHCs}$ (G). (N) Quantifications of OHC survival in different groups at P18. (P, Q) Representative images of caspase $3^{+}$cells (green) in GER of the apical turn of the control group at P6. (R, S) Representative images of caspase $3^{+}$cells in GER of apical turns in the P0group at P6. (T-W) Representative images of caspase ${ }^{+}$ cells in GER of apical turns in different groups at P11. (0) Quantifications of caspase ${ }^{+}$cells of GER in the apical turn of different groups at P6 and P11. *Significantly different from control group $(* \star P<0.01$, $\star \star \star P<0.001)$. Scale bar: $40 \mu \mathrm{m}(B, R, V)$. 

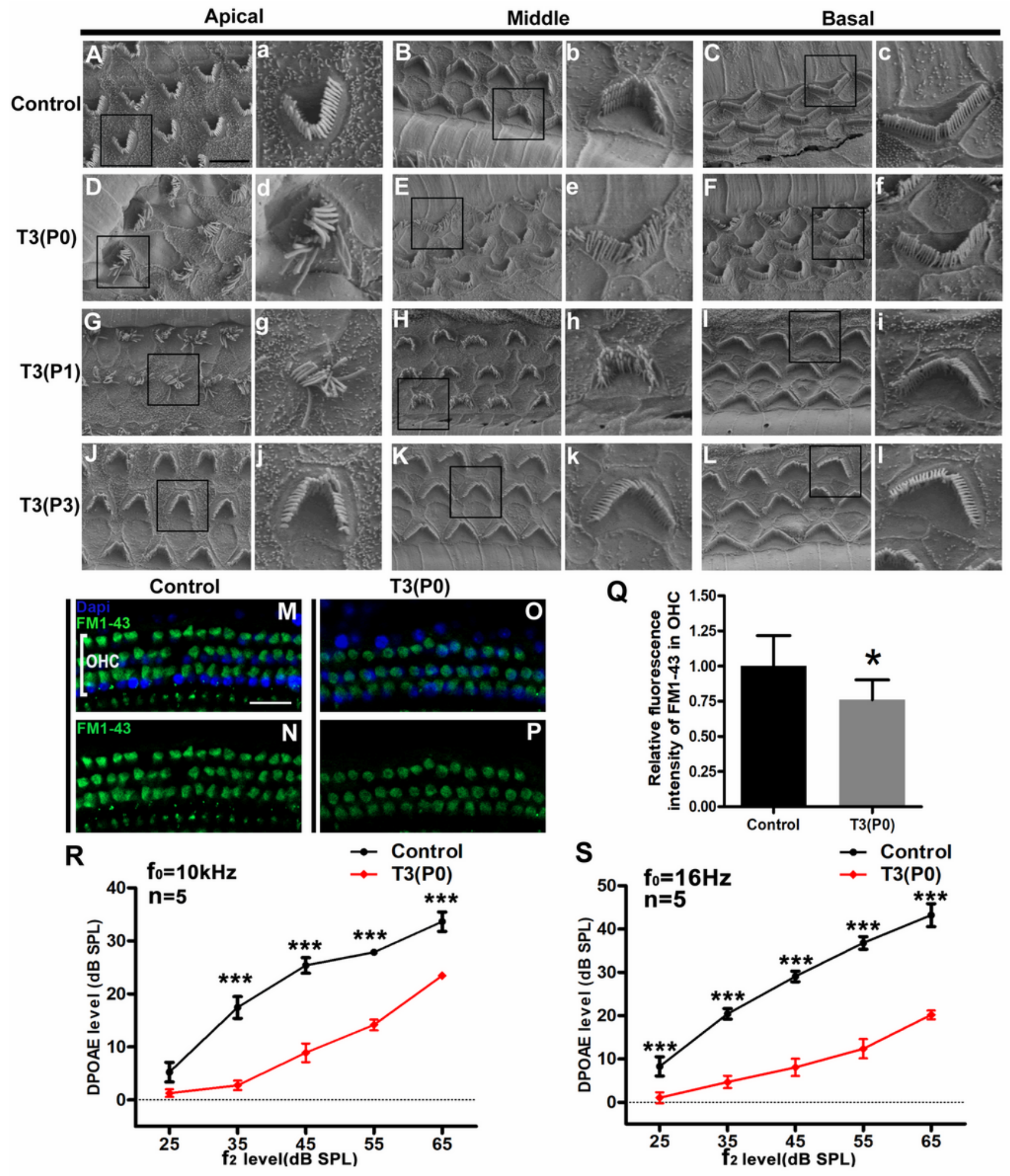

Figure 3

Excessive T3 interferes with the morphology of HC's stereocilia and the function of the MET channel (A-C) The morphology of HC's stereocilia in different turns of the control group. (a-c) Magnifications of the stereocilia in different turns of the control group. (D-L) Representative images of HC's stereocilia in the apical, middle, and basal turns of different T3 treated groups. (d-I) Magnified images show the morphology of the stereocilia in different groups. (M-P) Representative images of FM1-43 uptake by 
OHCs in the control and the P0 group. (Q) Quantification of FM1-43 fluorescence in OHCs in different groups. (R) The DPAOE input/output plots at $10 \mathrm{kHz}$. (S) The DPAOE input/output plots at $16 \mathrm{kHz}$. *Significantly different from control group ( $\left.{ }^{*}<0.05, * \star * P<0.001\right)$. The scales in the panel $A$ and $M$ represent 10 and $40 \mu \mathrm{m}$, respectively.
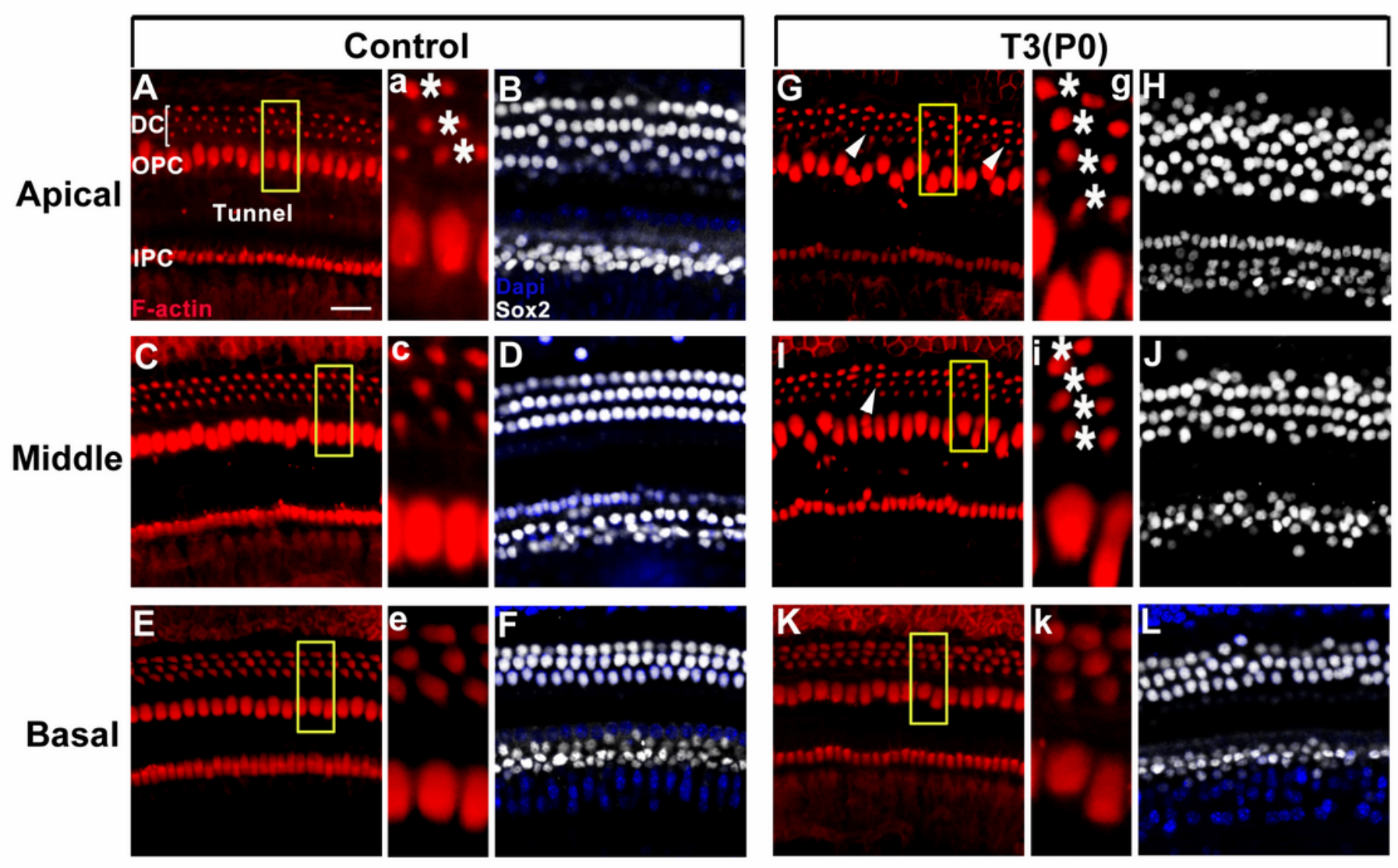

M
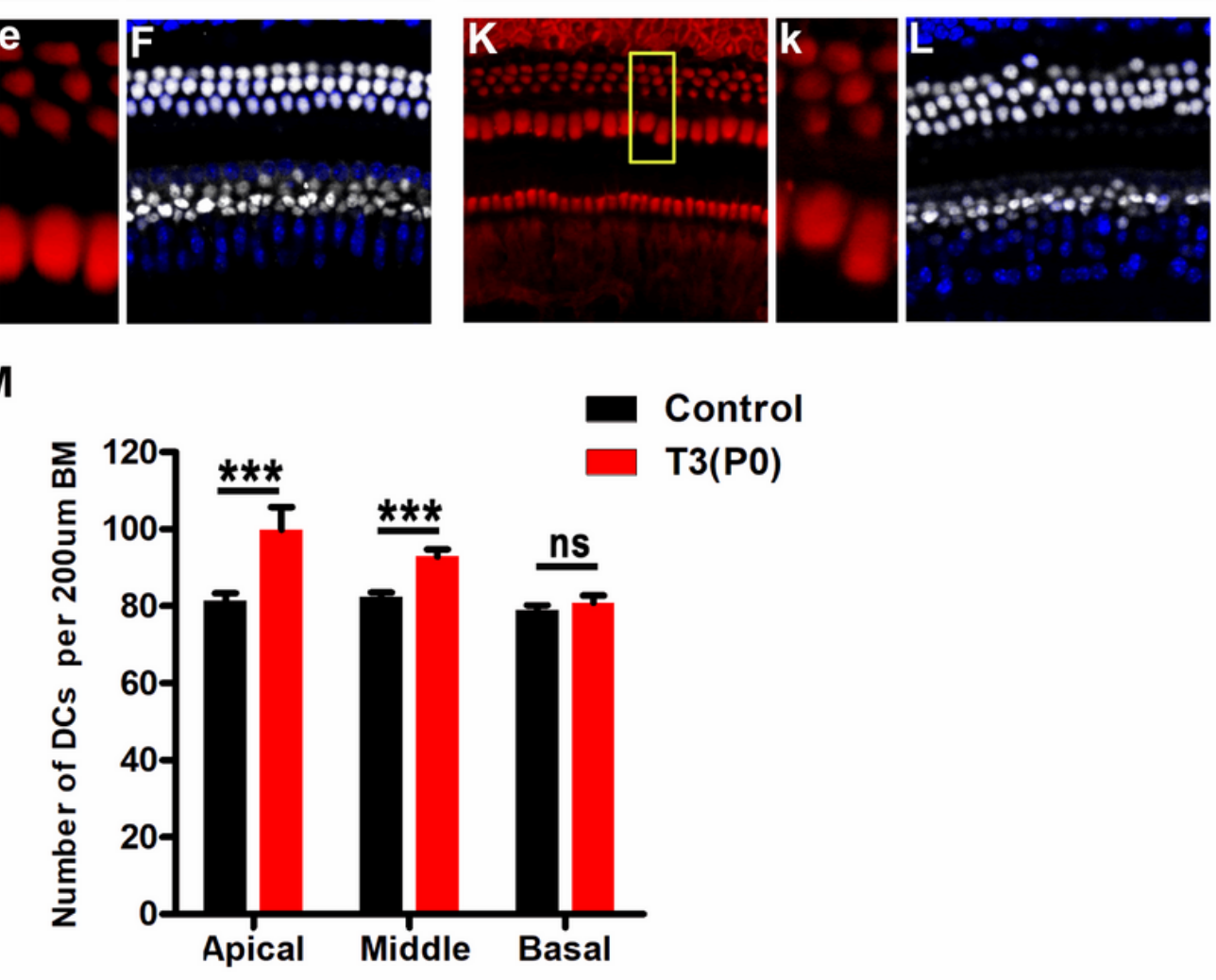

Figure 4

Excessive T3 can induce overproduction of DCs. (A, C, E) Representative images of DCs (F-actin, red) of different turns in the control group at P18. $(a, c, e)$ Magnified images of yellow boxes in the panel $A, C$, and $E$. * indicates the bottom of a DC. (B, D, F) Representative images of SCs (Sox2, white) of different 
turns in the control group at P18. $(\mathrm{G}, \mathrm{I}, \mathrm{K})$ Representative images of DCs (F-actin, red) of apical, middle and basal turns in the P0 group at P18. White arrowheads indicate extra DCs in the P0group (G and I). ( $\mathrm{g}$, $\mathrm{i}, \mathrm{k}$ ) Magnified images of yellow boxes in the panel $\mathrm{G}, \mathrm{I}$, and $\mathrm{K}$. * indicates that DCs are arranged in four rows in the apical and middle turn of the PO group $(\mathrm{g}, \mathrm{i}) .(\mathrm{H}, \mathrm{J}, \mathrm{L})$ Representative images of SCs of different turns in the P0group at P18. (M) Comparison of the number of DCs at specific cochlear locations in control and T3 treatment groups. ns: not significant, ${ }^{\star \star \star} P<0.001$. Scale bar: $40 \mu \mathrm{m}(\mathrm{A})$.
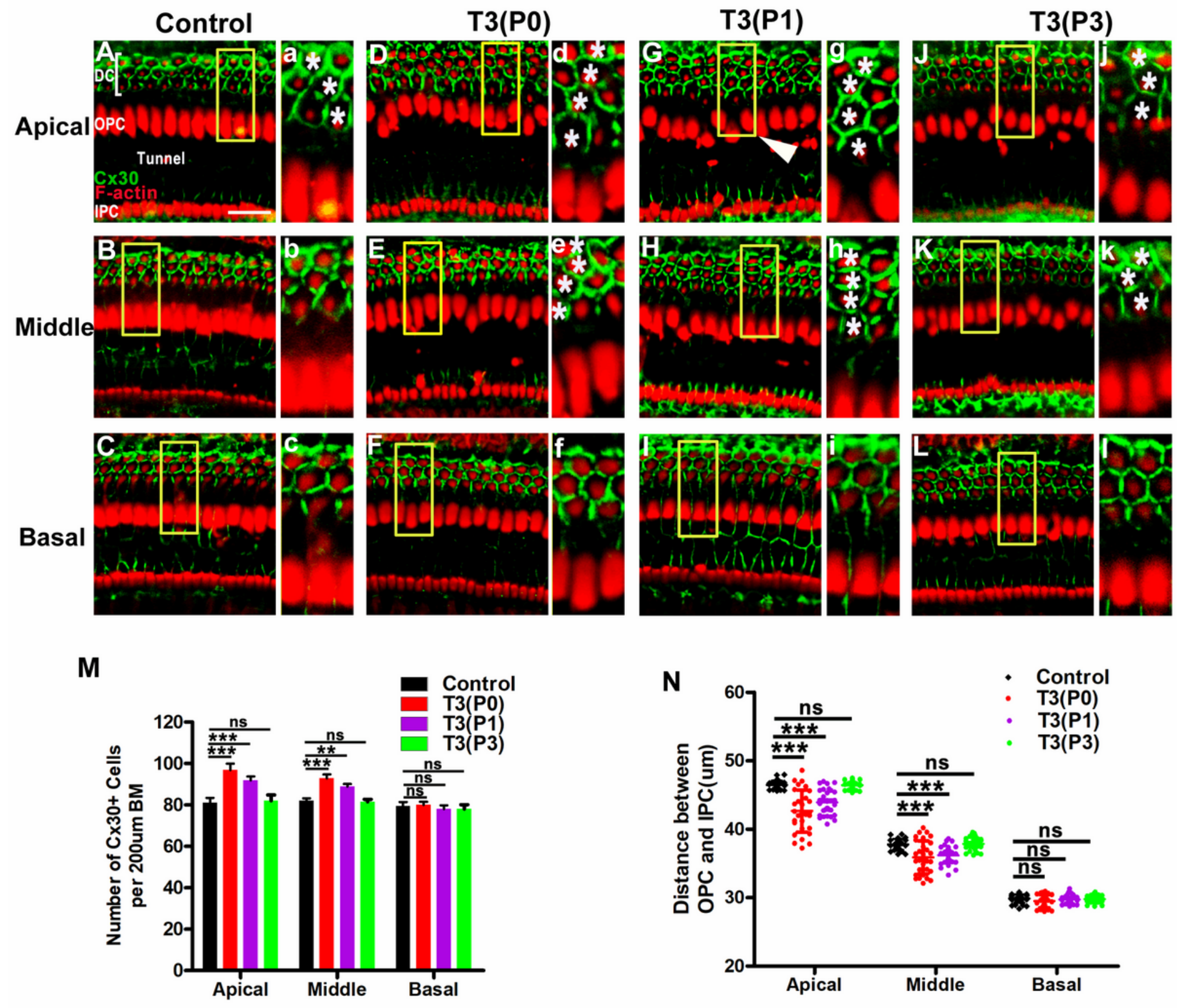

Figure 5

Extra DCs can be only induced by T3 in the early postnatal day. (A-C) F-actin (red) and Cx30 immunolabeling (green) in different turns of the control group, respectively. (a-c) Magnified images of yellow boxes in panel A-C. Asterisk indicates DCs were arranged in three rows in the control group (a). (D- 
F) Representative images of DCs and Cx30 expression patterns of different turns in the P0 group, respectively. (d-f) Magnified images of yellow boxes in panel D-F. The asterisk indicates the region in that DCs were arranged in four rows in the apical and middle turns (d, e). (G-I) Representative images of DCs and $\mathrm{Cx} 30$ expression patterns of different turns in the P1 group, (g-i) Magnified images of yellow boxes in panel G-I. (J-L) Representative images of DCs and Cx30 expression patterns of different turns in the P3 group, (j-I) Magnified images of yellow boxes in panel J-L. (M) Quantifications of the number of Cx30 + cells at specific cochlear locations in different groups at P18. (N) Comparison of the distance between the foot of IPC and OPC in different groups. ns: not significant, ${ }^{* \star} P<0.01, * \star \star P<0.001$. Scale bar: $40 \mu \mathrm{m}$ (A).
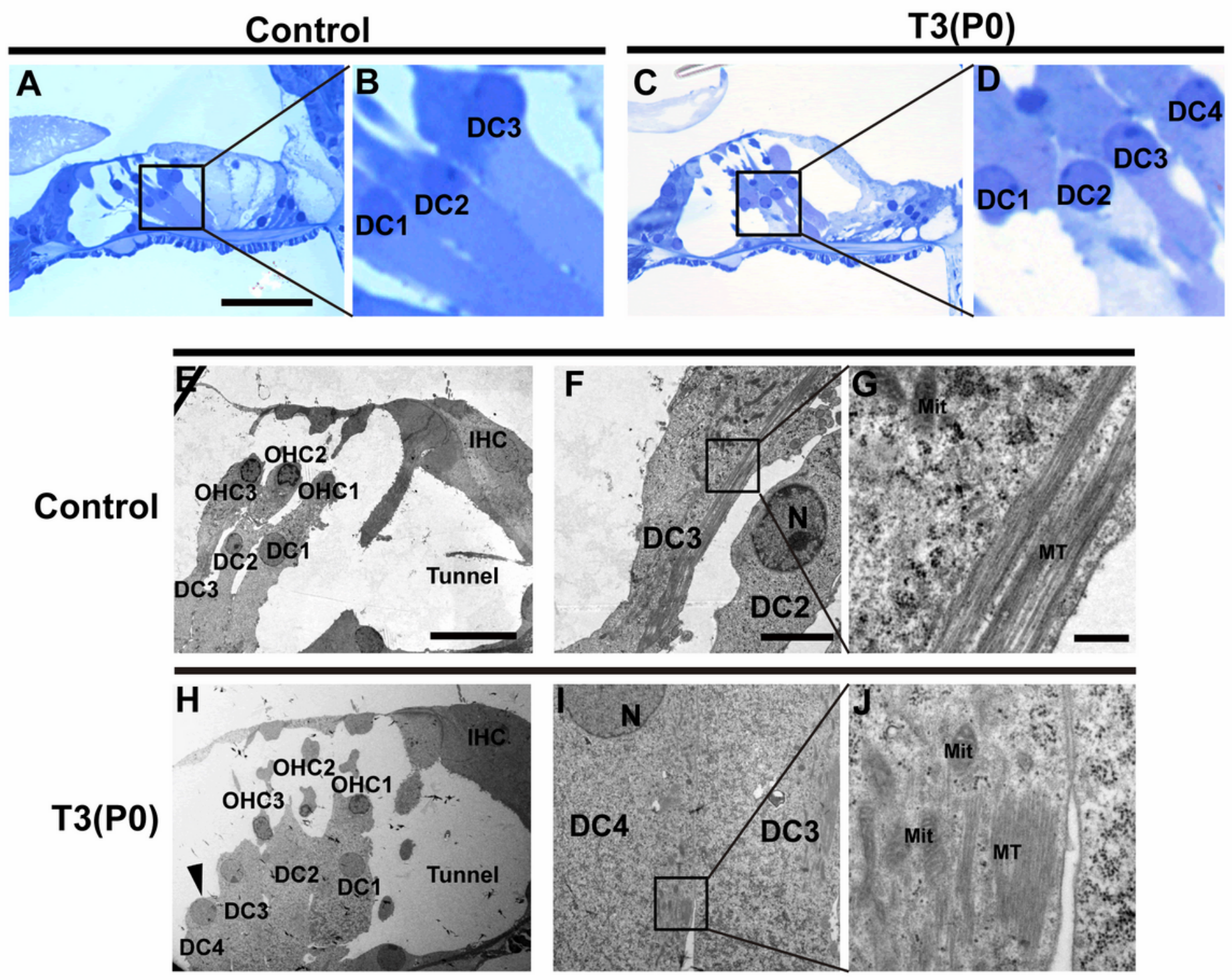

Figure 6

Ultrastructural observation of extra DCs (DC4) induced by T3. (A, C) The morphology of the OC in the apical of the control group and the P0 group at P18. (B, D) Magnified images of black boxes in the panel $A$ and $C$. (E) The ultrastructure of $O C$ in apical turns from the control group. $(F, G)$ Magnified images show 
the ultrastructural of DCs in the control group. $(\mathrm{H})$ The ultrastructure of $\mathrm{OC}$ in apical turns from the PO group. The black arrowhead in panel $\mathrm{J}$ indicates the extra DCs (DC4). $(I, J)$ Magnified images show the ultrastructural of DC4 in the T3 treatment group. The scales in the panel A, E, F, and G represent 40, 20, 5, and $0.5 \mu \mathrm{m}$, respectively. $\mathrm{N}$ : nucleus, MT: microtubule, Mit: mitochondria.

A
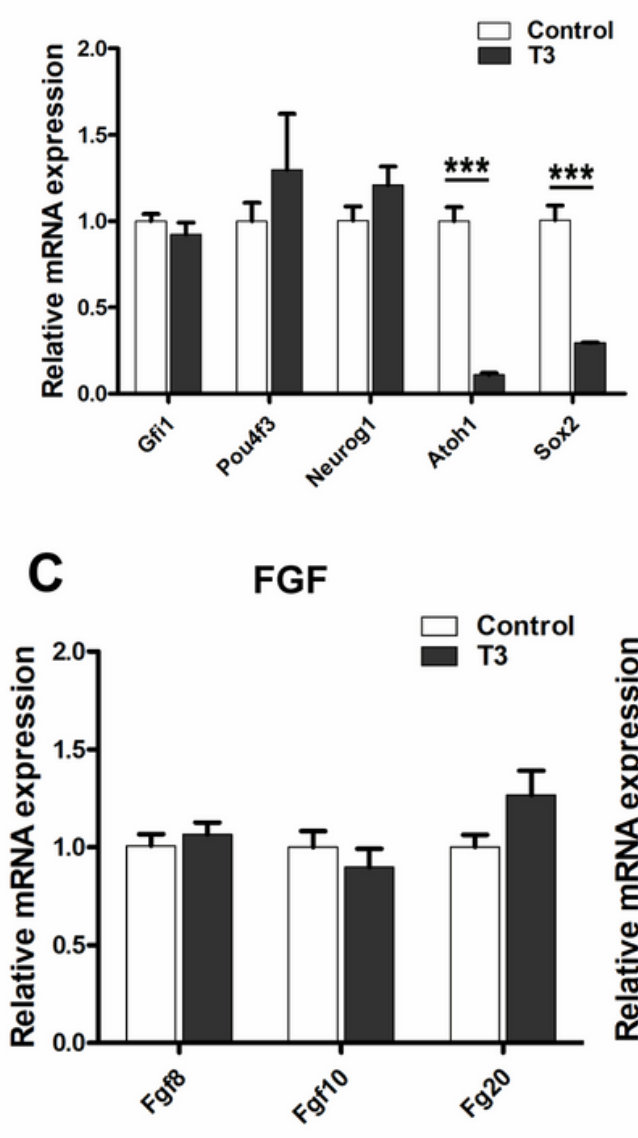

D

B
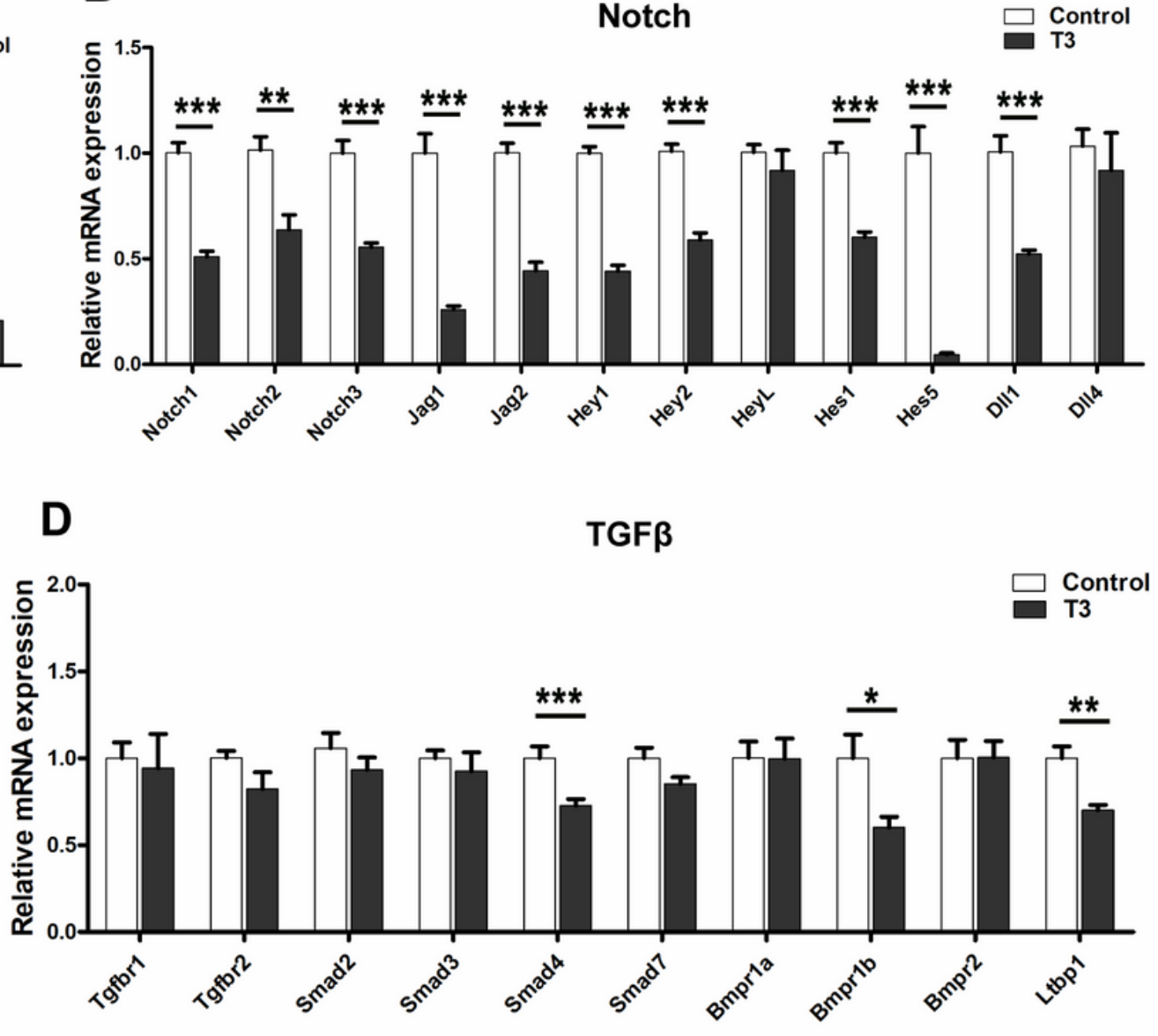

E

Wnt

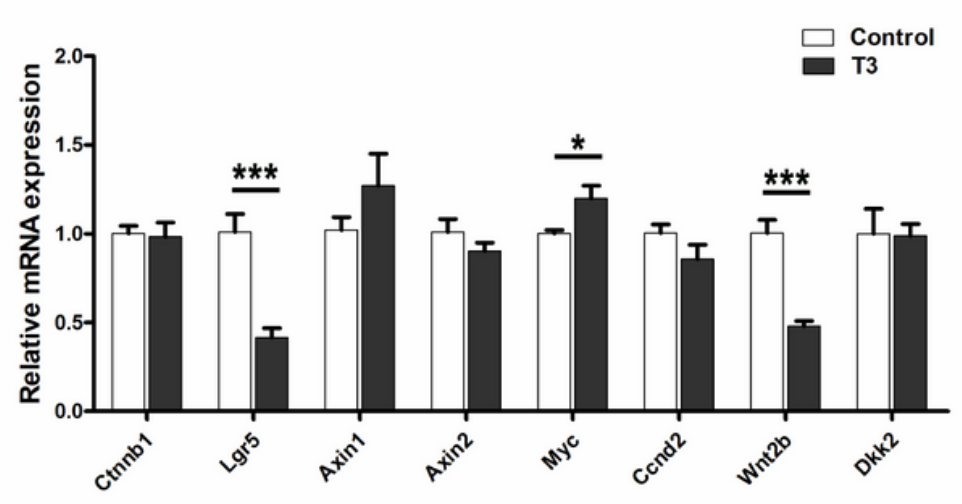

$\mathbf{F}$

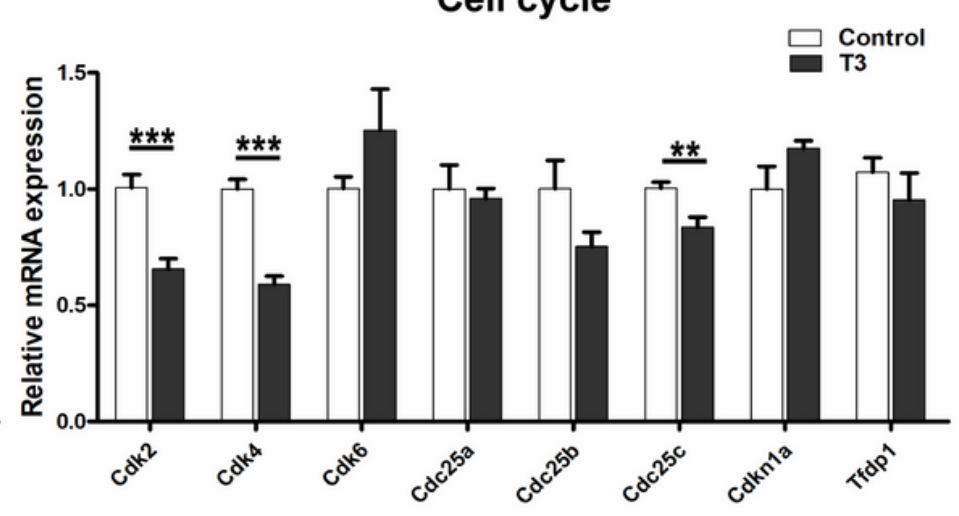

Figure 7 
Characterization of gene expression changes in the cochlea of T3 treated mice. (A-F) Relative mRNA expression levels of genes related to SCs development (A), Notch signaling (B), FGF signaling (C), TGF $\beta$ signaling (D), Wnt signaling (E), and cell cycle pathways $(F) .{ }^{*} P<0.05$, ${ }^{\star \star} P<0.01,{ }^{\star *} * \mathrm{P}<0.001$.
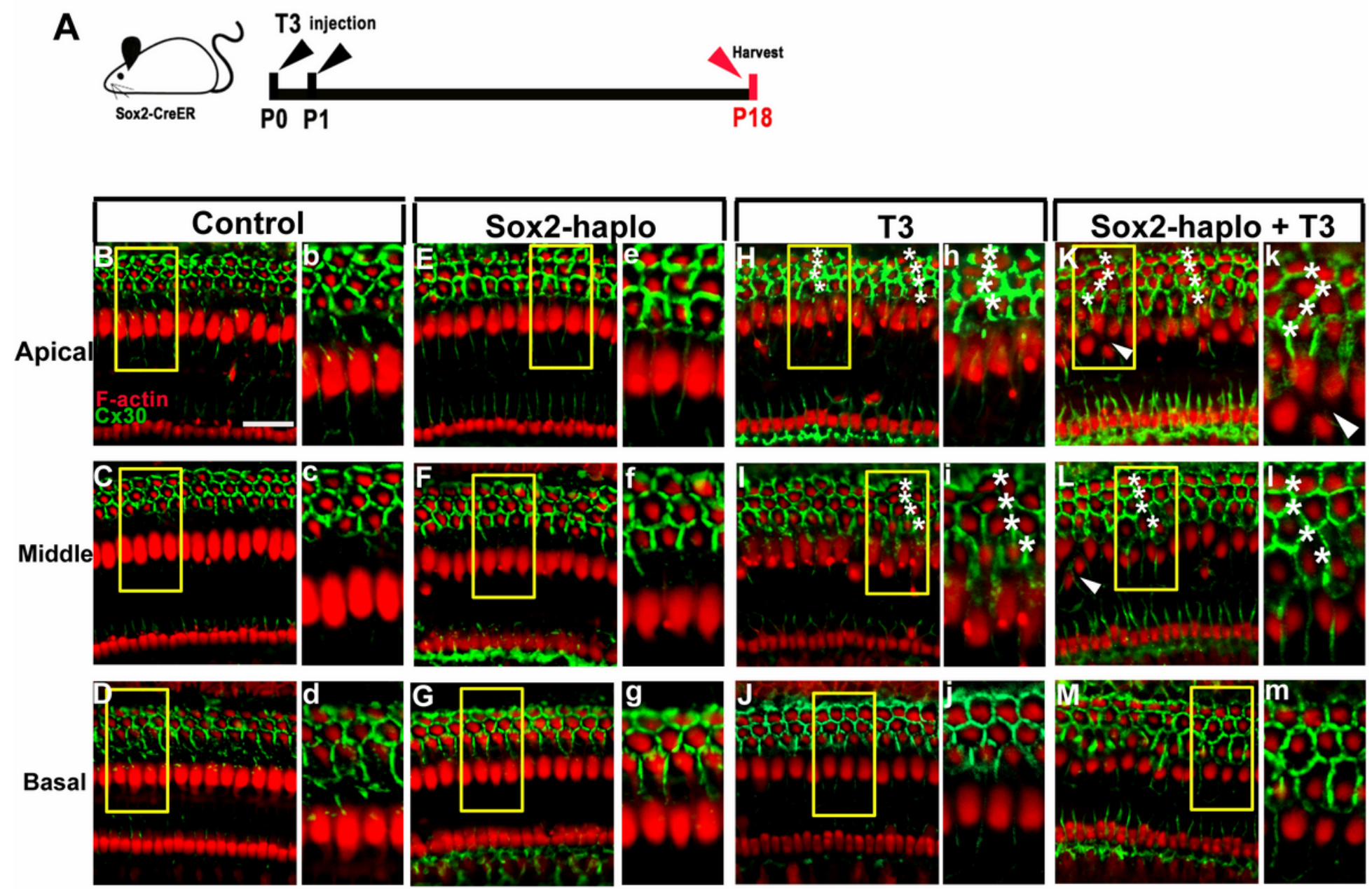

$\mathbf{N}$
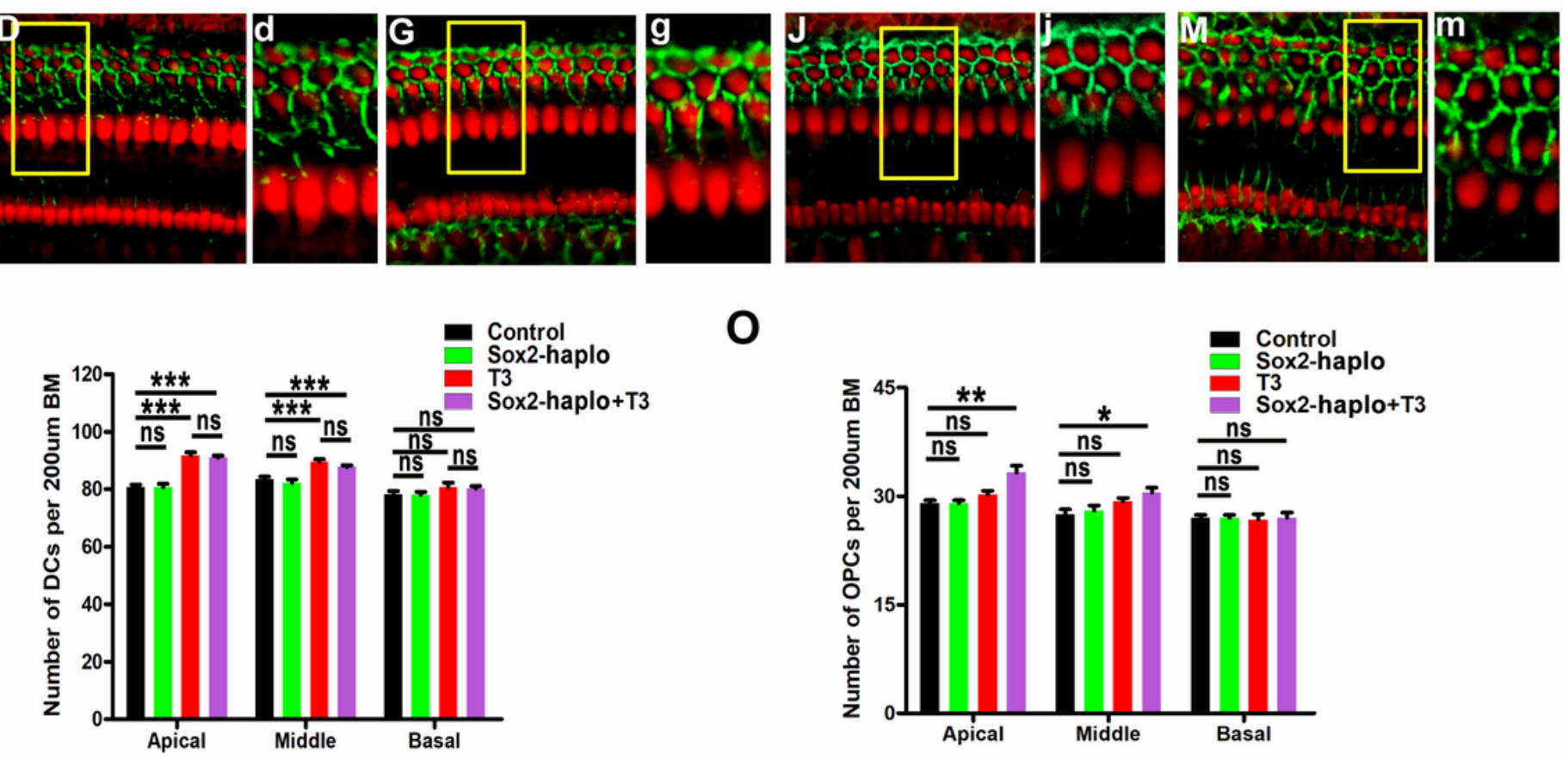

Figure 8

Effects of T3 combined with down regulating Sox2 on the remodeling of OC. (A) Sox2 haploinsufficiency mice were injected with $\mathrm{T} 3$ at P0 and P1, and sacrificed at P18. (B-D) F-actin (red) and Cx30 
immunolabeling (green) in different turns of the control group. (E-G) Representative images of DCs and Cx30 expression patterns of different turns of the Sox2 haplo group. (b-g) Magnified images of yellow boxes in panel B-G. (H-J) Representative images of DCs and Cx30 expression patterns of apical, middle, and basal turns of alone treated with T3 group, respectively. * indicates DCs were arranged in four rows in apical and middle turns of T3 alone treated group $(\mathrm{H}, \mathrm{l}, \mathrm{h}, \mathrm{i})$. (K-L) Representative images of DCs and Cx30 expression patterns in different turns of Sox2 haplo + T3 group. * indicates DCs were arranged in four rows in apical and middle turns $(K, L, k, I)$, and White arrowheads indicate the regions that OPCs were arranged in two rows in apical and middle turns $(K, L)$. (N) Comparison of the number of DCs at specific cochlear locations in the different groups. ( 0 ) Comparison of the number of OPCs at specific cochlear locations in the different groups. ns: not significant, ${ }^{\star \star *} P<0.001,{ }^{\star *} P<0.01,{ }^{*} P<0.05$. Scale bar: $40 \mu \mathrm{m}$ (B). 

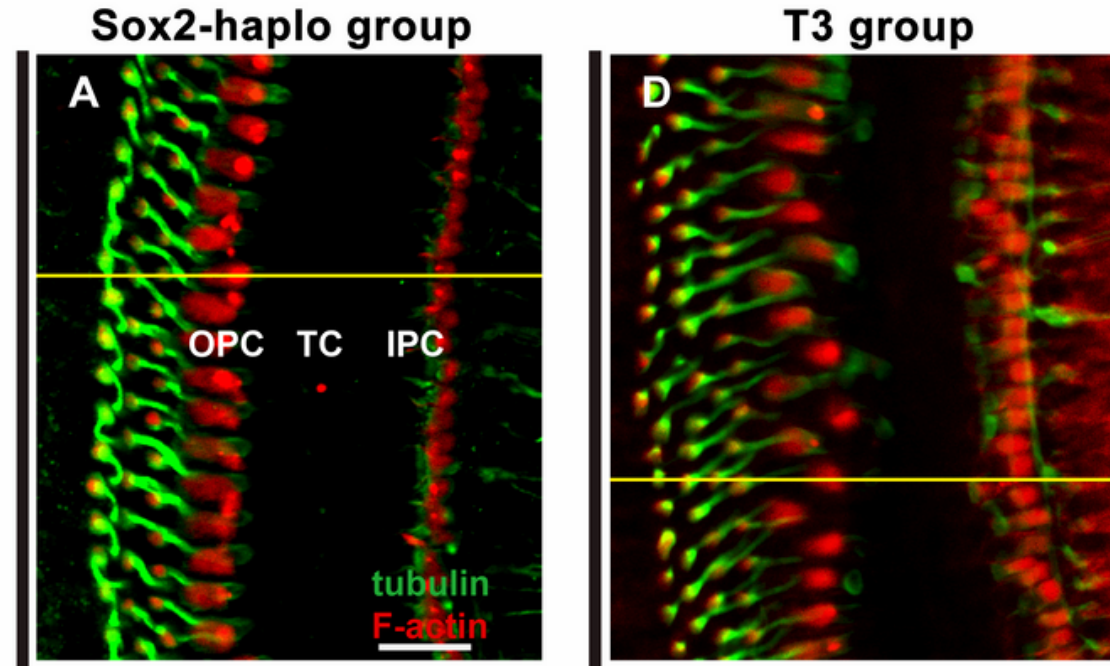

Sox2-haplo + T3 group
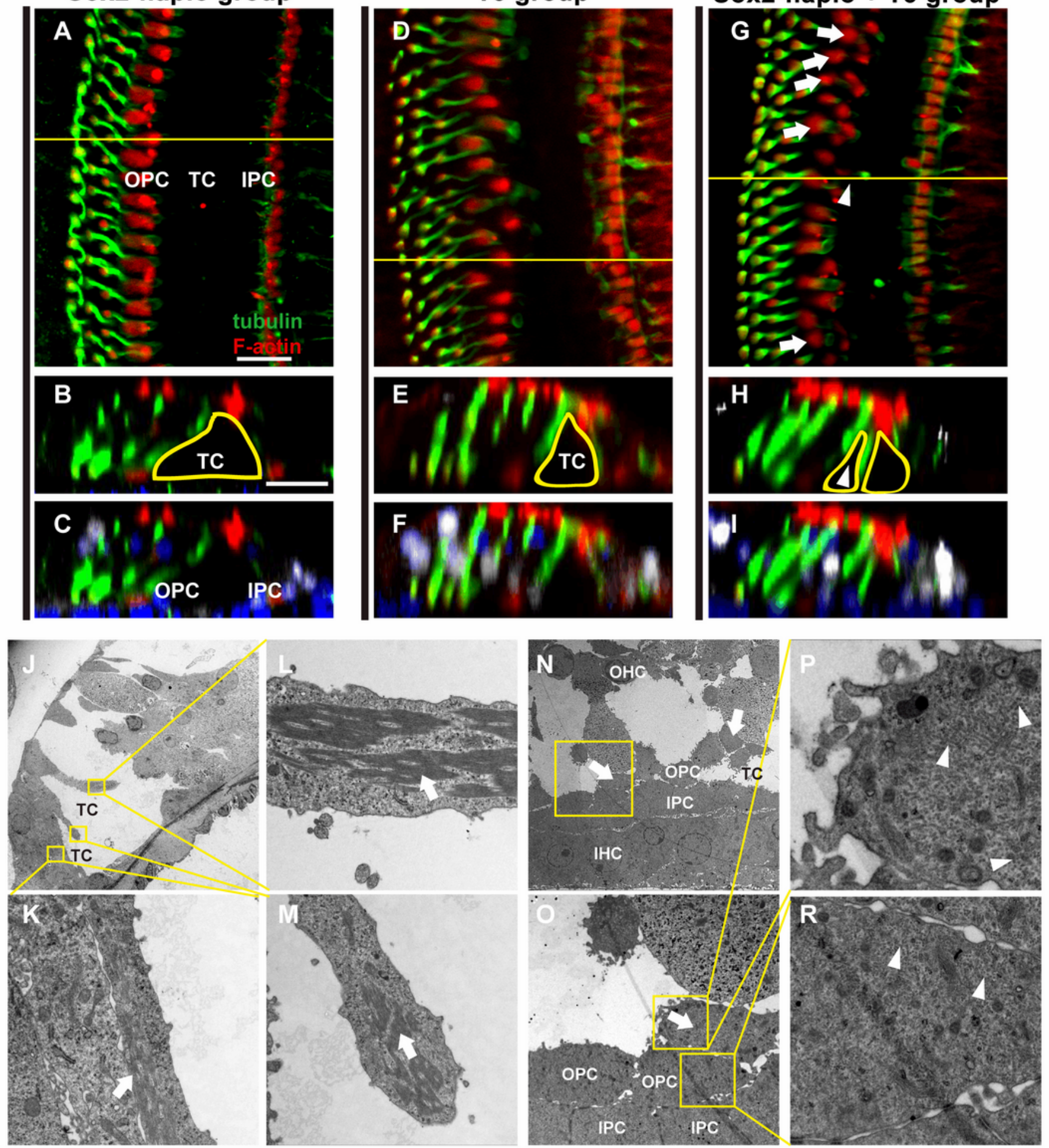

Figure 9

The combination of T3 and Sox2 haploinsufficiency induced the remodeling of Tunnei of Corti. (A-F) Factin (red) and acetylated a-tubulin immunolabeling (green) in apical of the Sox2 halpo or T3 group, and cross-sectional views were generated to show the morphology of the OC. (G-I) F-actin and acetylated atubulin immunolabeling in the apical turn of the Sox2 halpo + T3 group, and cross-sectional views were generated to show the morphology of the OC. White arrows indicate the regions that OPCs were arranged 
in two rows, white arrowheads indicate the newly formed tunnels of Corti. $(\mathrm{J})$ The morphology of the OC in the apical turn of the Sox2 halpo + T3 group. $(K, M, L)$ Magnified images of yellow boxes in panel $J$. White arrows indicate the microbundles of PC. (N) Horizontal sections of the cochlea to show the morphology of the OC in the Sox2 halpo + T3 group. (0) Magnified images of yellow boxes in panel $\mathrm{N}$, white arrows indicate the additional OPC. $(P, R)$ Magnified images of yellow boxes in panel $O$, white arrowheads indicate numerous microbundles. Scale bar: $40 \mu \mathrm{m}(\mathrm{A}, \mathrm{B})$.

\section{Supplementary Files}

This is a list of supplementary files associated with this preprint. Click to download.

- FigureS1.tif

- SupplementaryTable1.docx 